\title{
The Association of Pension Income with the Incidence of Type I Obesity among Retired Israelis
}

\author{
Yuval Arbel (D), ${ }^{1}$ Chaim Fialkoff, ${ }^{2}$ and Amichai Kerner ${ }^{3}$ \\ ${ }^{1}$ Sir Harry Solomon School of Economics and Management, Western Galilee College, Acre 2412101, Israel \\ ${ }^{2}$ Institute of Urban and Regional Studies, Hebrew University of Jerusalem, Mt. Scopus, Jerusalem 9190501, Israel \\ ${ }^{3}$ School of Real Estate, Netanya Academic College, 1 University Street, Netanya 4223587, Israel \\ Correspondence should be addressed to Yuval Arbel; yuval.arbel@gmail.com
}

Received 4 November 2018; Revised 14 April 2019; Accepted 22 May 2019; Published 25 July 2019

Academic Editor: David H. St-Pierre

Copyright ( $\odot 2019$ Yuval Arbel et al. This is an open access article distributed under the Creative Commons Attribution License, which permits unrestricted use, distribution, and reproduction in any medium, provided the original work is properly cited.

Previous studies have identified obesity and overweight as the fourth leading risk factor for global mortality. The objective of the current study is to investigate gender differences and the impact of wealth and income from pensions, sociodemographic variables, and self-assessment of health conditions on the projected probability to become obese in the postretirement age (67 years and older). We are unaware of previous studies, which explored the direct relationship between obesity, monetary income from pensions, wealth, and self-assessment of health conditions. To conduct this research, we make use of an extensive questionnaire concerning the economic and sociodemographic features and health and housing conditions of individuals administered within the framework of the 2015-2016 longitudinal survey conducted by the Israeli Central Bureau of Statistics (CBS). The survey is representative of the Israeli population and also includes information regarding the weight, height, gender, and age of each household member. Results of our study demonstrate that while for the female respondents older than 67, the projected probability of type I obesity (BMI $\geq 30)$ drops by $0.41 \%(p=0.0021)$ to $0.52 \%(p=0.0001)$ with an incremental 10,000 NIS (about $\$ 2,500)$ rise of gross annual income from a pension, for the male respondents above 67 years, the projected probability remains unchanged ( $p=0.4225$ ). This outcome remains robust even when the 2015 BMI measurement of type I obesity (BMI $\geq 30)$ is controlled. This drop among women attenuates with a cutoff point increase from BMI $\geq 25$ (overweight) to BMI $\geq 30$ (type I obesity) to BMI $\geq 35$ (type II obesity). Further results indicate that for both genders above 67 years and for men above 62 years, the projected BMI drop of one year decreases with income from a pension ( $p=0.013, p=0.039$, and $p=0.007$, respectively), although the spread around the projection becomes wider. Compared with other martial status categories, for widowed females, the projected probability of obesity and self-reporting on improved health conditions drops by $6.58 \%(p=0.0419)$ to $11.28 \%$ $(p=0.0048)$ and $6.55 \%(p=0.0190)$ to $7.47 \%(p=0.0036)$, respectively. For females older than 67 , family status divorced $d r o p s$ the projected probability of obesity by $9.25 \%(p=0.0319)$. For males older than 67 , results show a rise in projected obesity with car ownership by $6.10 \%(p=0.0897)$ to $6.41 \%(p=0.0469)$ and a drop in projected obesity with academic degree status by $9.93 \%$ $(p=0.0106)$ to $10.14 \%(p=0.0118)$ and immigration status from American-European countries by $7.67 \%(p=0.0821)$ to $8.99 \%$ $(p=0.0398)$ and Asian-African countries by $11.63 \%(p=0.0245)$ to $11.99 \%(p=0.02)$. Research findings stress the differences and similarities in male-female patterns of obesity after the retirement age of 67 years and may be of assistance to welfare and public health experts.

\section{Introduction}

Previous studies have identified obesity and overweight as the fourth leading risk factor for global mortality, responsible for an estimated number of 3.2-5.0 million deaths annually $[1,2]$. Recently, Nyberg et al. [3] estimated the loss of disease-free years associated with class II-III obesity $\left(\mathrm{BMI} \geq 35, \quad \mathrm{BMI}=\right.$ Weight $\div\left(\mathrm{Height}^{2}\right)$, where Weight is measured in kilograms and Height is measured in meters) to range between 7.1 and 10.0 years in subgroups of participants of different socioeconomic status categories, levels of physical activity, and smoking habits. 
Following Arbel et al. [4], the objective of the current study is to investigate gender differences and the impact of wealth and monetary income from pensions, sociodemographic variables, and self-assessment of health conditions on the projected probability to become obese in the postretirement age (above 67 years). Given the public expenses associated with increasing life expectancy in Western countries, the study of this cohort might prove to be important in formulating more focused and effective public policies and programs. To the best of our knowledge, these relationships have not been previously explored in the context of gender differences in the postretirement age. The current literature addresses the impact of retirement and occupation on body weight, while a few studies made use of income categories rather than precise monetary income (e.g., [5-9]).

To conduct this research, we make use of an extensive set of questions concerning the economic and sociodemographic features and health and housing conditions of each respondent asked within the framework of the 2015-2016 longitudinal survey conducted by the Israeli Central Bureau of Statistics (CBS). The survey is representative of the Israeli population and includes information regarding the weight, height, gender, and age of each household member.

A common and accepted measure of classifying bodyweight uses BMI. This investigation uses definitions proposed by the World Health Organization, obesity and overweight. Key facts: overweight (BMI $\geq 25)$, type I obesity $(\mathrm{BMI} \geq 30)$, and type II obesity $(\mathrm{BMI} \geq 35)$ (available at https://www.who.int/en/news-room/fact-sheets/detail/ obesity-and-overweight; accessed at March 28)[10].

Results of our study demonstrate that while for the female respondents above 67 years, the projected probability of type I obesity $(\mathrm{BMI} \geq 30)$ drops with an incremental 10,000 NIS (about $\$ 2,500$ ) rise of gross annual income from a pension by $0.41 \%(p=0.0021)$ to $0.52 \%(p=0.0001)$, for the male respondents above 67 years, the projected probability remains unchanged $(p=0.4225)$. This outcome remains robust even when the 2015 BMI measurement of type I obesity $(B M I \geq 30)$ is controlled. This drop in the female group attenuates with a cutoff point increase from BMI $\geq 25$ (overweight) to $\mathrm{BMI} \geq 30$ (type I obesity) to BMI $\geq 35$ (type II obesity). Further results indicate that compared with other martial status categories, for widowed females, the projected probability of obesity and self-reporting on improved health conditions drops by $6.58 \%(p=0.0419)$ to $11.28 \%$ $(p=0.0048)$ and $6.55 \%(p=0.0190)$ to $7.47 \%(p=0.0036)$, respectively. For females older than 67 , the family status divorced drops the projected probability of obesity by $9.25 \%$ $(p=0.0319)$.

For males above 67, the outcomes demonstrate a rise in projected obesity with car ownership by $6.10 \%(p=0.0897)$ to $6.41 \%(p=0.0469)$ and a drop in projected obesity with academic degree status by $9.93 \%(p=0.0106)$ to $10.14 \%$ $(p=0.0118)$ and immigration status from American-European by $7.67 \%(p=0.0821)$ to $8.99 \%(p=0.0398)$ and Asian-African countries by $11.63 \%(p=0.0245)$ to $11.99 \%$ $(p=0.02)$.

Finally, for both genders above 67 years and for men above 62 years, a projected BMI drop of one year decreases with income from a pension $(p=0.013, p=0.039$, and $p=0.007$, respectively), although the spread around the projection becomes wider.

Research findings stress the differences and similarities in male-female patterns of obesity after the retirement age of 67 years and may be of assistance to welfare and public health experts.

The rest of this paper is organized as follows. Section 2 provides an analytical framework. Section 3 (Materials and Methods (A): A Comparison between Two Consecutive Years) provides descriptive statistics, presents the empirical model, and reports the results, where the data are arranged to permit testing the BMI change across one year and to control type I obesity (BMI $\geq 30$ ) measured in 2015. Section 4 (Materials and Methods (B): A Conventional Analysis of Panel Data) applies the analysis to a conventional panel data structure and provides robustness tests where the cutoff point definition of obesity changes from $B M I \geq 25$ (overweight) to $\mathrm{BMI} \geq 30$ (type I obesity) to $\mathrm{BMI} \geq 35$ (type II obesity). Finally, Section 5 (Discussion) concludes and summarizes.

\section{Analytical Framework}

A long-debated question in the literature is the relationship between mortality rates, health, and wealth, and, in particular, "what do the gaps in health have to do with gaps in income?" ([11], page 113). In an influential study and by logistic curve-fitting based on cross-sectional average data at the country level for the years 1900, 1930, and 1960, Preston [12] demonstrated (1) a positive relationship between life expectancy at birth and GDP per capita at a decreasing pace and (2) an upward curve shift from 1930 to 1960. Following Preston [12], the conventional assumption that income is the most important cause of mortality decline has been an unquestioned starting point. Deaton [13], for example, indicated that "people whose reported family incomes in 1980 were less than $\$ 5,000$ in 1980 prices are estimated to have a life expectancy around 25 percent lower than those whose family incomes were above $\$ 50,000 "$ (page 13). On the contrary, given that many health improvements that have been achieved are relatively inexpensive, Deaton concludes that cross-country mortality differences are not the direct outcomes of income inequality but rather of government institutional efficiency. The same institutional characteristics that make countries good at producing output make them good at providing clean water and access to medical care ([11], page 113). Moreover, in a recent study, Lutz and Kebede [14] have demonstrated that the important explanatory variable is the education level rather than the income level.

Referring specifically to the BMI measure and obesity, Subramanian et al. [15], who explored cross-country differences in height, found a strong positive association between height and household wealth. The authors conclude that "Socioeconomic inequalities in height remain persistent. Height has stagnated or declined over the last decades in low- to middle-income countries, particularly in Africa, suggesting worsening nutritional and environmental 
circumstances during childhood" (quoted from the abstract of the article). Jolliffe [16] addresses the claim that according to the United States National Health and Nutrition Examination Survey (NHANES) data, the null hypothesis of the same overweight rates across income levels cannot be rejected at any time in the last 35 years. Given the nonsymmetrical BMI distribution, the author uses quantile regression and demonstrates that for those at the tails of the BMI distribution, increases in income are correlated with healthier BMI values. [17] demonstrate that at a macrolevel of OECD countries, excluding USA and Mexico (which lead the obesity chart and exhibit obesity rates of $40 \%$ ), no association was found between obesity and income inequality in OECD countries.

Finally, Zagorsky [18] found a 12\% (7\%) decrease of projected net worth of white (black) women with 1-unit increase in BMI. Lee [19] demonstrated that for both genders at the 51-64-year-old cohort in the USA, the shift from zero or negative net worth to positive net worth is associated with a decrease in the projected probability of type I obesity.

\section{Materials and Methods (A): A Comparison between Two Consecutive Years}

The objective of the current section is to explore gender differences and the relationship between BMI change and income from a pension. The data are arranged in a way that each variable is related to one specific year, (either 2016 or 2015). On the one hand, this data structure enables the following:

(1) Testing the relationship between BMI2016 and BMI2015 (the BMI of the same person in two consecutive years).

(2) Calculating the percent of change as BMI_PER = $100 \cdot[($ BMI2016/BMI2015) -1$]$.

(3) Testing the difference between female and male BMI distribution for 2016 and 2015.

(4) Analyzing the relationships between BMI_PER, INCPENS2016, and BMI30_2015, a dummy variable that equals one where BMI $2015 \geq 30$ (type I obesity according to Nyberg et al. [3]) and zero otherwise.

On the other hand, this data structure accounts only for individuals with BMI information on both 2016 and 2015 waves. Consequently, in subsequent sections, we apply the analysis to a conventional panel data structure.

3.1. Sample and Controls. The data for this study are based on the longitudinal survey carried out by the Israeli CBS in 2014-2015 and 2016. As an OECD member since 2010, Israel is required to conduct such a survey.

The sample of this survey is representative of the Israeli population, which includes all the Israeli households and persons living in nontherapeutic institutions (students in dormitories, assisted living for the elderly, and absorption centers for new immigrants). The definition of the Israeli population excludes prisoners, inhabitants in therapeutic institutions, such as chronic care housing for the elderly, Israeli inhabitants who remained outside the country for at least one year, foreign workers, diplomats, and Bedouins living in scattered settlements in the southern part of Israel.

The common method used to collect the data from the sampled households is face-to-face interviews at the respondents' homes via computerized questionnaires. Each adult household member above 17 years old was interviewed in one of three languages (Hebrew, Arabic, and Russian).

Given that several studies in the field use telephone interviews (e.g., $[20,21]$ ), the face-to-face interview technique provides two main advantages: (1) unlike phone interviews, the respondent is more likely to answer the questionnaire in a nonthreatening environment with reduced tendency to avoid answers; (2) the interviewer can assess the reliability of answers, particularly regarding environmental housing conditions and height and weight of each household member; (3) families who are sampled by the Israeli CBS are required to cooperate by law. Consequently, high cooperation rates are achieved.

The short term follow up (one year) makes the data structure somewhat similar to a cross section. Molina-Garc et al. [22] and Sallis et al. [1, 23] compared between countries, cities, and individuals based on cross-sectional studies. Nevertheless, the use of one-year follow-up still permits the exploration of the relationship between the BMI of the same person in two consecutive years. Consequently, even the one-year follow-up is somewhat (slightly) better than a cross-sectional study.

Table 1 displays the frequencies of the raw sample based on availability of data with respect to the height and weight variables. From these variables, we measure the BMI as Weight $\div\left(\right.$ Height $\left.^{2}\right)$. The relevant cohorts of our study are above 67 years old (the retirement age for Israeli males) and above 62 years old (the retirement age for the Israeli females). As can be seen from the table, information regarding these variables is available for more than $90 \%$ of the respondents. The apparent reason for these high cooperation rates is the legal requirement to cooperate by law with the interviewers.

Tables 2 and 3 report the descriptive statistics referring separately to $841(1,305)$ respondents above $67(62)$ years with weight and height measured in both the 2016 and 20142015 waves. As previously noted, the former (latter) group consists of $70.91 \%-74.79 \%(74.49 \%-74.06 \%)$ of those who had at least one BMI report either in the 2016 or 2014-2015 waves. Consequently, the information loss associated with the current data structure is $25.21 \%-29.09 \%$ (25.51\%$25.94 \%$ ) - at least one-quarter of the original sample.

The average BMI measured in the 2016 wave is $27.12-$ 27.18 (BMI2016) and that in the 2014-2015 wave is 27.1427.18 (BMI2015). The average BMI increase within one year is $0.18 \%-0.28 \%$ and the standard deviation is $8.57 \%-8.60 \%$ (BMI_PER). Based on the cutoff points defined by Nyberg et al. [3] of BMI $\geq 25$ (overweight), BMI $\geq 30$ (type I obesity), and BMI $\geq 35$ (type II obesity), 65\%-66\% are overweight and above (BMI25_2015; BMI25_2016), 23\% have type I obesity and above (BMI30_2015; BMI30_2016), and 6\%-7\% suffer from type II obesity (BMI35_2015; BMI35-2016). 
TABLE 1: Frequencies of the raw sample with respect to weight and height.

\begin{tabular}{|c|c|c|c|c|}
\hline & Available & Unknown & Refusal & Total sample \\
\hline \multicolumn{5}{|l|}{ Weight2016 } \\
\hline Above $67(N)$ & 1,196 & 74 & 14 & 1,284 \\
\hline Above $67(\%)$ & 93 & 6 & 1 & 100 \\
\hline Above $62(N)$ & 1,745 & 97 & 32 & 1,874 \\
\hline Above $62(\%)$ & 93 & 5 & 2 & 100 \\
\hline \multicolumn{5}{|l|}{ Height2016 } \\
\hline Above $67(N)$ & 1,186 & 94 & 4 & 1,284 \\
\hline Above 67 (\%) & 92 & 8 & 0 & 100 \\
\hline Above $62(N)$ & 1,753 & 112 & 9 & 1,874 \\
\hline Above $62(\%)$ & 94 & 6 & 0 & 100 \\
\hline \multicolumn{5}{|l|}{ Weight2015 } \\
\hline Above $67(N)$ & 1,131 & 83 & 17 & 1,231 \\
\hline Above $67(\%)$ & 92 & 7 & 1 & 100 \\
\hline Above $62(N)$ & 1,762 & 105 & 28 & 1,895 \\
\hline Above $62(\%)$ & 93 & 6 & 1 & 100 \\
\hline \multicolumn{5}{|l|}{ Height2015 } \\
\hline Above $67(N)$ & 1,129 & 97 & 5 & 1,231 \\
\hline Above $67(\%)$ & 92 & 8 & 0 & 100 \\
\hline Above $62(N)$ & 1,782 & 105 & 8 & 1,895 \\
\hline Above $62(\%)$ & 94 & 6 & 0 & 100 \\
\hline
\end{tabular}

Note. (1) The full sample of the above 67 years old cohort in the 2016 wave (2014-2015 wave) includes 1,284 (1,237) persons. (2) The full sample of the above 62 years old cohort in the 2016 wave (2014-2015 wave) includes 1,875 (1,901) persons. (3) Individuals with "unknown" or "refusal" classifications have been deleted from the sample. (4) Of the 1,186 (1,129) persons above 67 years with available information on BMI in 2016 wave (2014-2015 wave), 841 persons, consisting of 70.91\% (74.49\%), had available BMI information on both 2016 and 2014-2015 waves. (5) Of the 1,745 (1,762) persons above 62 years with available information on BMI in 2016 wave (2015 wave), 1,305 persons, consisting of 74.79\% (74.06\%), had available BMI information on both 2016 and 20142015 waves.

TABLe 2: Descriptive statistics of 2015-2016 panel: pooled sample above 67 years.

\begin{tabular}{|c|c|c|c|c|}
\hline Variables & Description & Obs. & Mean & $(\mathrm{SD})$ \\
\hline Weight 2016 & $\begin{array}{l}\text { Weight in kg with light clothing and no shoes } \\
\text { measured in the } 2016 \text { wave }\end{array}$ & 841 & 74 & $(14.2)$ \\
\hline Height 2016 & $\begin{array}{l}\text { Height in centimeters without shoes measured in the } \\
\qquad 2016 \text { wave }\end{array}$ & 841 & 165 & $(9.0)$ \\
\hline BMI2016 & Body mass $=10,000 \cdot\left(\right.$ Weight $2016 /$ Height $\left.2016^{2}\right)$ & 841 & 27 & $(4.8)$ \\
\hline Weight 2015 & $\begin{array}{l}\text { Weight in } \mathrm{kg} \text { with light clothing and no shoes } \\
\text { measured in the } 2015 \text { wave }\end{array}$ & 841 & 74 & $(14.1)$ \\
\hline Height2015 & $\begin{array}{l}\text { Height in centimeters without shoes measured in the } \\
\qquad 2015 \text { wave }\end{array}$ & 841 & 165 & $(9.0)$ \\
\hline BMI2015 & Body mass $=10,000 \cdot\left(\right.$ Weight $2015 /$ Height $\left.2015^{2}\right)$ & 841 & 27 & $(4.7)$ \\
\hline BMI_PER & (BMI2016/BMI2015) -1 & 841 & $0.18 \%$ & $(8.6 \%)$ \\
\hline BMI25_2015 & $1=\mathrm{BMI} \geq 25 ; 0=\mathrm{BMI}<25$ & 841 & $65 \%$ & $(48.0 \%)$ \\
\hline BMI30_2015 & $1=\mathrm{BMI} \geq 30 ; 0=\mathrm{BMI}<30$ & 841 & $23 \%$ & $(42.0 \%)$ \\
\hline BMI35_2015 & $1=\mathrm{BMI} \geq 35 ; 0=\mathrm{BMI}<35$ & 841 & $7 \%$ & $(25.0 \%)$ \\
\hline Age2015 & Age in years & 841 & 75 & $(4.4)$ \\
\hline Females2015 & $1=$ females $; 0=$ males & 841 & $53 \%$ & $(50.0 \%)$ \\
\hline GET_PENSION2016 & $1=$ get pension $; 0=$ otherwise & 841 & $38 \%$ & $(68.0 \%)$ \\
\hline INCPENS2016 >0 & $\begin{array}{l}\text { Household's annual gross monetary income from } \\
\text { pensions in NIS for the household }\end{array}$ & 322 & 86,023 & $(91,832.0)$ \\
\hline
\end{tabular}

Figure 1 displays the distribution of BMI2016 and BMI2015 on the same graph and the distribution of BMI differences in percentage points. The null hypothesis average $($ BMI2016) $=$ average $($ BMI2015) cannot be rejected. The respective $p$ values for the above 62 -year-old and 62year-old cohorts are 0.6025 and 0.4998 .

Returning to Tables 2 and 3, four additional variables are age, gender, percentage of individuals with income from pension, and the amount received only for the latter group of individuals. Depending on the lower bound of the age restriction (Age $>62$ or Age $>67$ ), the average age in 2015 is $71.29-74.70$ and the maximum age is 80 years (Age2015). $52 \%-53 \%$ of the sample is females (Females2015). Finally, of the pooled sample, $36 \%-38 \%$ receive income from a pension (GET_PENSION2016), and the annual amount received is $84,933-86,023$ NIS, the local Israeli currency, where 1 NIS $\approx 0.25$ US Dollars (INCPENS2016). Given that the average worker earnings is 


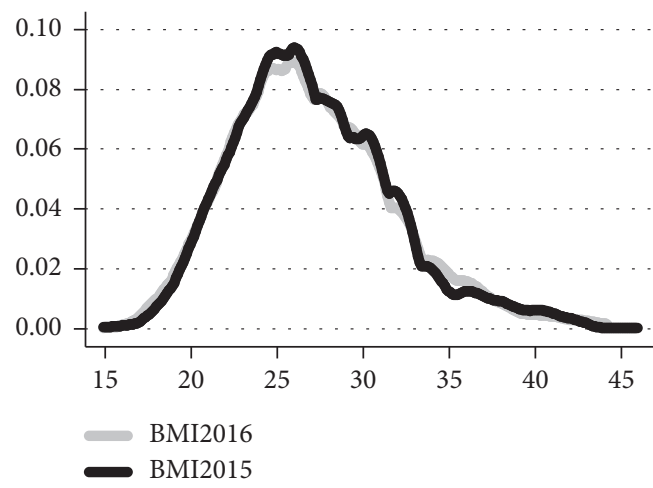

(a)

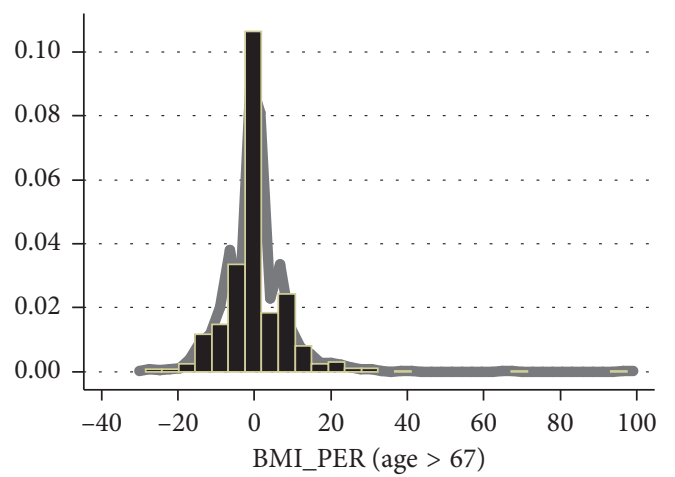

(c)

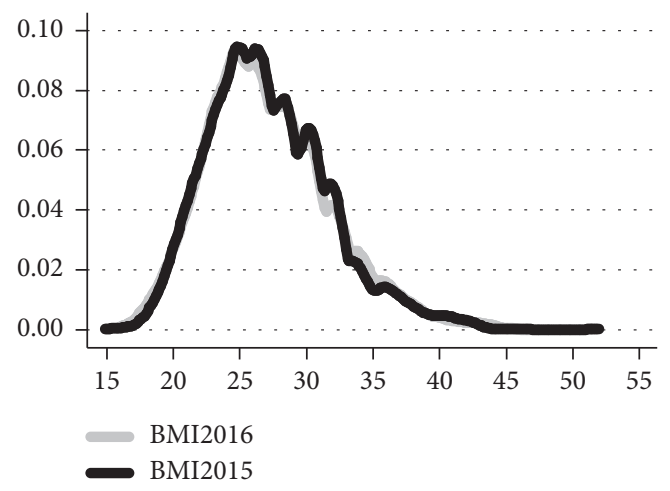

(b)

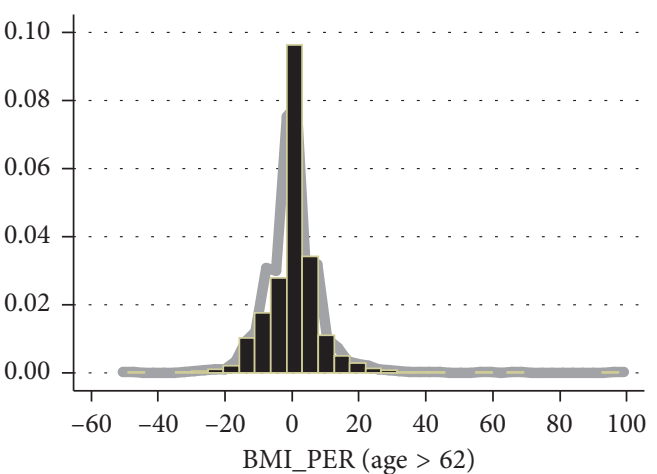

(d)

Figure 1: Distribution of BMI2016 vs. BMI2015: pooled sample. Note: the figures refer to the pooled sample of 841 $(1,305)$ women and men above 67 years (above 62 years) with available information on BMI2016 and BMI2015. Given that the retirement age for men (women) in Israel is 67 years (62 years), these ages were chosen as the cutoff points. BMI_PER equals 100 - [(BMI2016/BMI2015) - 1]. For the above 67 years cohort (above 62 years cohort), the null hypothesis, average(BMI2016) = average(BMI2015) cannot be rejected. The $p$ value is 0.6025 (0.4998).

TABLE 3: Descriptive statistics of 2015-2016 panel: pooled sample above 62 years.

\begin{tabular}{|c|c|c|c|c|}
\hline Variables & Description & Obs. & Mean & $(\mathrm{SD})$ \\
\hline Weight2016 & $\begin{array}{l}\text { Weight in kg with light clothing and no shoes } \\
\text { measured in the } 2016 \text { wave }\end{array}$ & 1,305 & 75 & $(14.5)$ \\
\hline Height2016 & $\begin{array}{l}\text { Height in centimeters without shoes measured in the } \\
\qquad 2016 \text { wave }\end{array}$ & 1,305 & 166 & $(9.0)$ \\
\hline BMI2016 & Body mass $=10,000 \cdot\left(\right.$ Weight2016/Height $\left.2016^{2}\right)$ & 1,305 & 27 & $(4.7)$ \\
\hline Weight 2015 & $\begin{array}{l}\text { Weight in kg with light clothing and no shoes } \\
\text { measured in the } 2015 \text { wave }\end{array}$ & 1,305 & 75 & $(14.3)$ \\
\hline Height 2015 & $\begin{array}{c}\text { Height in meters without shoes measured in the } 2015 \\
\text { wave }\end{array}$ & 1,305 & 166 & $(9.0)$ \\
\hline BMI2015 & Body mass $=10,000 \cdot($ Weight2015/Height2015²) & 1,305 & 27 & $(4.6)$ \\
\hline BMI_PER & $($ BMI2016/BMI2015) -1 & 1,305 & $0.28 \%$ & $(8.6 \%)$ \\
\hline BMI25_2015 & $1=\mathrm{BMI} \geq 25 ; 0=\mathrm{BMI}<25$ & 1,305 & $66 \%$ & $(48.0 \%)$ \\
\hline BMI30_2015 & $1=\mathrm{BMI} \geq 30 ; 0=\mathrm{BMI}<30$ & 1,305 & $23 \%$ & $(42.0 \%)$ \\
\hline BMI35_2015 & $1=\mathrm{BMI} \geq 35 ; 0=\mathrm{BMI}<35$ & 1,305 & $6 \%$ & $(25.0 \%)$ \\
\hline Age2015 & Age in years & 1,305 & 71 & $(5.9)$ \\
\hline Females 2015 & $1=$ females $0=$ males & 1,305 & $52 \%$ & $(50.0 \%)$ \\
\hline GET_PENSION2016 & $1=$ get pension; $0=$ otherwise & 1,305 & $36 \%$ & $(48.0 \%)$ \\
\hline INCPENS2016>0 & $\begin{array}{l}\text { Household's annual gross monetary income from } \\
\text { pensions in NIS for the household }\end{array}$ & 464 & 84,933 & $(95,758.0)$ \\
\hline
\end{tabular}

Note. The sample includes $841(1,305)$ individuals for whom both BMI2016 and BMI2015 are available, and with age restriction above 67 years old (above 62 years old), participating in the 2015-2016 longitudinal survey carried out by the Israeli CBS. The lower age bound is based on the retirement age from the workforce, which is 67 years old for males and 62 years for females. NIS is the local Israeli currency, where 1 NIS roughly equals $\$ 0.25$. Standard deviations are given in parentheses. 
142,247 NIS [24], incomes from pensions in the sample consist of $59.71 \%-60.47 \%$ of the average annual salary. In this context, currently, the pension system in Israel is compulsory, and the target is to reach $70 \%$ of the last salary before retirement based on 2\% annual deposit during 35 years of employment. Consequently, and assuming that prior retirement salary is 142,247 NIS, the $59.71 \%-60.47 \%$ is lower than the desired $70 \%$.

Figure 2 displays the distributions of BMI2016 and BMI2015 based on gender differences. We compare the distributions of Age $>67$, the postretirement cohorts in 2015, to $20<$ Age $\leq 67$, the preretirement cohorts for both genders in 2015. To test the male-female BMI differences, we run a Kolmogorov-Smirnoff (K-S) test. The calculated statistics for this test is the maximum BMI difference between the male-female distributions. Results of this test show that with the exception of the Age $>67$ group and 2016 measure ( $p=0.165)$, for all the remaining groups, the maximum BMI difference between the male-female distributions is statistically different from zero $(p=0.026$ and $p<0.0001$, respectively) Table 4 .

As an interim summary, we have demonstrated that the average BMI measure in 2016 and 2015 is equal, and there are BMI gender differences. The next step is to examine the relationship between the BMI variables and the INCPENS (income from pension) variable.

3.2. The Empirical Model. Consider the following independent equations estimated separately for above 67-yearold and above 62-year-old males and females:

$$
\begin{aligned}
\text { BMI2016 }= & \alpha_{0}+\alpha_{1} \text { BMI30_2015 } \\
& +\alpha_{2}\left(\text { INCPENS2016 } \div\left(10^{4}\right)\right)+\alpha_{3} \text { BMI30_2015 } \\
& \cdot\left(\text { INCPENS2016 } \div\left(10^{4}\right)\right)+\mu_{1},
\end{aligned}
$$

$$
\begin{aligned}
\mathrm{BMI} \_\mathrm{PER}= & \beta_{0}+\beta_{1} \mathrm{BMI} 30 \_2015 \\
& +\beta_{2}\left(\mathrm{INCPENS} 2016 \div\left(10^{4}\right)\right)+\beta_{3} \text { BMI30_2015 } \\
& \cdot\left(\operatorname{INCPENS} 2016 \div\left(10^{4}\right)\right)+\mu_{2},
\end{aligned}
$$

where BMI2016 and BMI_PER are the dependent variables; BMI30_2015 and INCPENS2016 $\div\left(10^{4}\right)$ are the independent variables; $\alpha_{0}, \alpha_{1}, \alpha_{2}, \alpha_{3}$ and $\beta_{0}, \beta_{1}, \beta_{2}, \beta_{3}$ are parameters; and $\mu_{1}, \mu_{2}$ are the classical random disturbance terms.

3.3. Results. Figure 3 shows the projected BMI in 2016 as a function of income from a pension based on the estimation of equation (1). Only for women, the projected BMI drops with income from a pension ( $p=0.022$ for females above 67 years and $p=0.049$ for females above 62 years). (Based on the recommendations of the American Statistical Association (ASA), throughout the article we refrain from using the terminology "statistically [in] significant" and report instead calculated $p$ values (see $[25,26]$ and Wasserstein et al. [27] and, in particular, the recommendation given on page 12 . We thank an anonymous reviewer for directing our attention to this issue.) As the figure demonstrates, the spread around the projection becomes wider with higher income from a pension, indicating more heterogeneity in the BMI measure (BMI between 16.75 and 25.90 for above 62-year-old women with annual income from a pension of 1 million NIS). As for men, the projected BMI remains unchanged with income from a pension $(p=0.908$ for males above 67 years and $p=0.566$ for males above 62 years).

Figure 4 shows the projected BMI change during one year as a function of income from a pension based on the estimation of equation (1). The graph also presents the $95 \%$ confidence interval around each projection. Based on the graph data, Tables 5 and 6 provide numerical examples for 62-year-old women and men. Results demonstrate that, on the one hand, for both genders above 67 years and for men above 62 years, the projected BMI change drops with higher income from a pension $(p=0.013, p=0.039$, and $p=0.007$, respectively). On the other hand, the spread around the projection becomes wider with higher income from a pension, indicating more heterogeneity in BMI change (between $0.70 \%$ and $22.53 \%$ drop for above 67 -year-old women with annual income from a pension of 1 million NIS).

Tables 5 and 6 demonstrate that there are no contradictions between Figures 3 and 4:

As can be seen from this example, both BMI2016 and percent of BMI change drop with the shift from no annual income to 1 million NIS annual income from a pension.

As can be seen from this example, while BMI2016 rises with the shift from no annual income to 1 million NIS annual income from a pension, the percent of BMI change drops with the shift from no annual income to 1 million NIS annual income from a pension.

\section{Materials and Methods (B): A Conventional Analysis of Panel Data}

4.1. Descriptive Statistics. Tables 7 and 8 present the descriptive statistics of the pooled sample after arrangement based on the conventional panel data structure. The table refers to 1,771 respondents $\times$ years. The respondents $\times$ years are distributed to 921 (850) females $\times$ years (males $\times$ years) belonging to 507 (466) households, where the age of both genders was restricted to those older than 67 years, participating in the 2015-2016 longitudinal survey carried out by the Israeli CBS. The lower age bound is based on the retirement age from the workforce, which is 67 years old for males.

According to the OECD report referring to Israel, life expectancy at birth is 82.7 years, compared to 80.9 years in the OECD countries, and life expectancy at age 65 years is 20.6 additional years, compared with 19.7 additional years in the OECD countries. The direct implication from these figures is the required public finance of 20 years after retirement. The age for eligibility for a pension has been increasing gradually since 2004 with increases from 65 to 67 years for men and from 60 years to 62 years for women. Men's retirement age reached 67 years in 2009 while women's is currently 62 and projected to increase to 64 by 2022 . Moreover, the percent of 


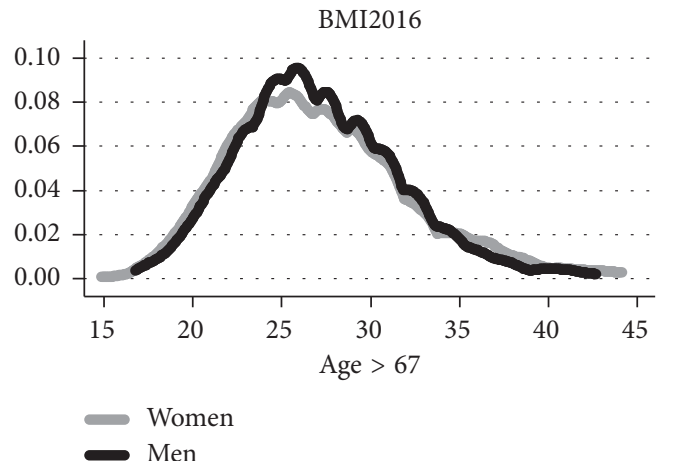

(a)

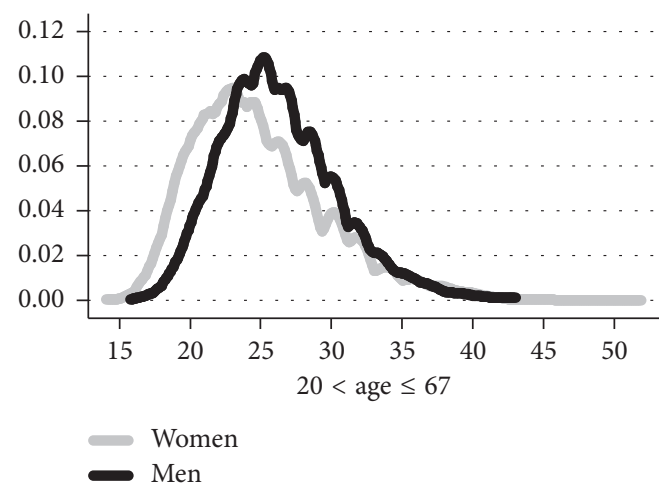

(c)

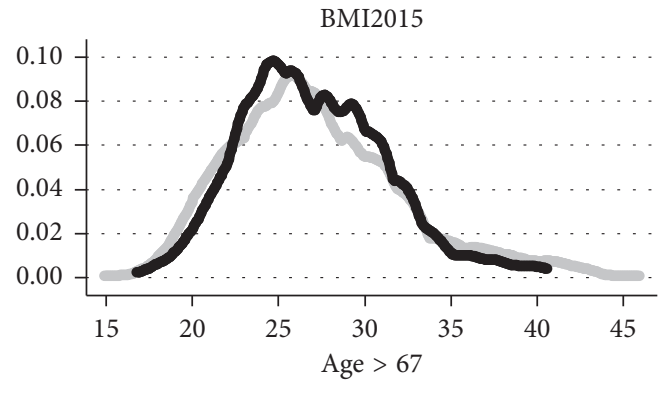

Women

$\longrightarrow$ Men

(b)

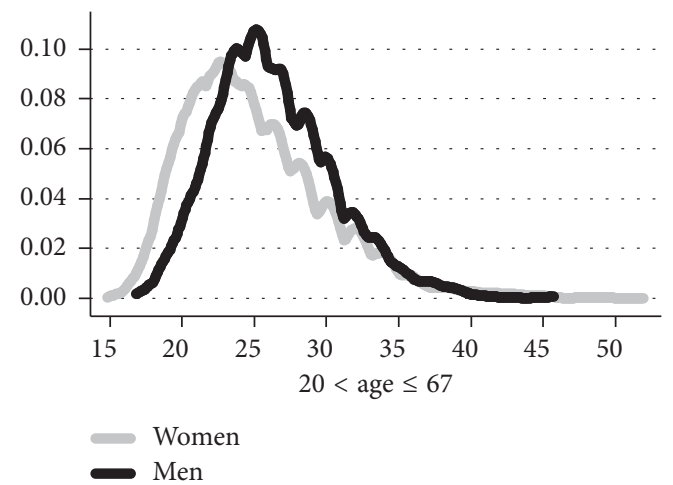

(d)

Figure 2: Distribution of BMI2016 and BMI2015 females vs. males. Note. The figure compares BMI2016 and BMI2015 of women and men above and below 67 years with available information on BMI2016 and BMI2015. Given that the retirement age for men in Israel is 67 years, this age was chosen as the cutoff point.

TABle 4: The Kolmogorov-Smirnoff (K-S) test measures the maximum difference between the female-male distributions $(D)$. Results of the combined K-S test are given in the following table.

\begin{tabular}{lccc}
\hline Cohort & Observations & BMI2016 & BMI2015 \\
\hline Age $>67$ & $N=841 ;$ females $=447 ;$ males $=394$ & $D=0.0772(p$ value $=0.165)$ & $D=0.1017^{* *}(p$ value $=0.026)$ \\
$20<$ Age $\leq 67$ & $N=4,400 ;$ females $=2,214 ;$ males $=2,186$ & $D=0.2086^{* * *}(p<0.0001)$ & $D=0.2127^{* * *}(p<0.0001)$ \\
\hline
\end{tabular}

${ }^{* *} p<0.05$ for male-female BMI difference. ${ }^{* * *} p<0.01$ for male-female BMI difference.

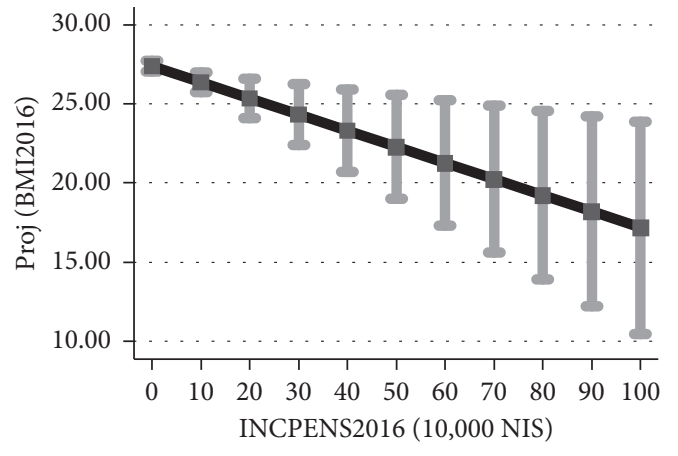

(a)

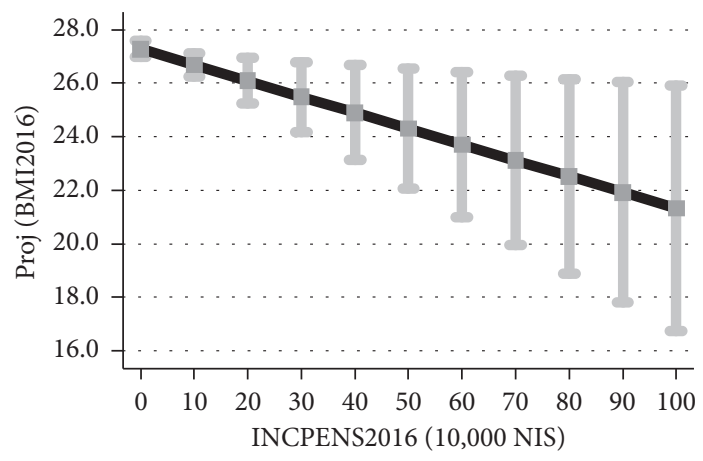

(b)

Figure 3: Continued. 


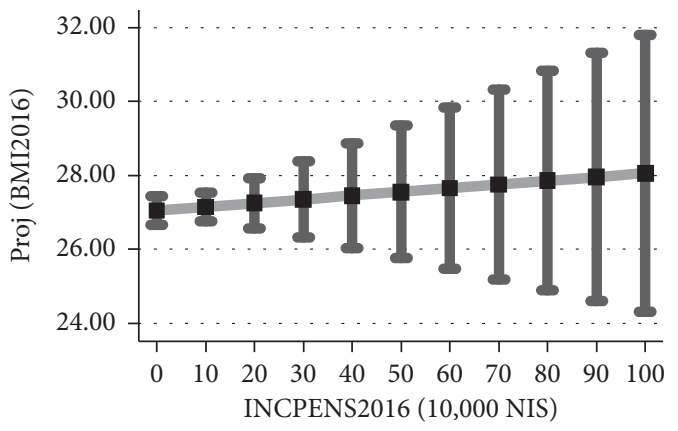

(c)

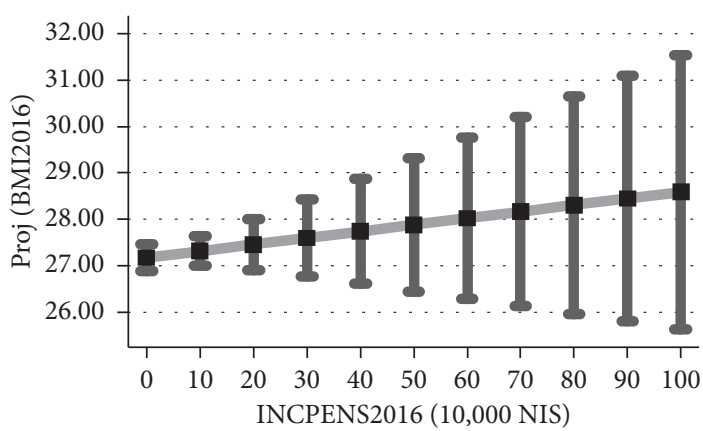

(d)

FIgURE 3: Projected BMI vs. income from a pension in 2016. Note. The figure is based on the regression outcomes available upon request based on the model given by equation (1). The vertical axis in each graph is the projected BMI measured in 2016 and the $95 \%$ confidence interval for each level of income from a pension. The horizontal axis is income from a pension, measured in 10,000 NIS $(10=100,000$ NIS; $100=1,000,000$ NIS). NIS is the local Israeli currency ( 1 NIS $\approx 0.25$ US dollars). (a) Women above 67 years. (b) Women above 62 years. (c) Men above 67 years. (d) Men above 62 years.

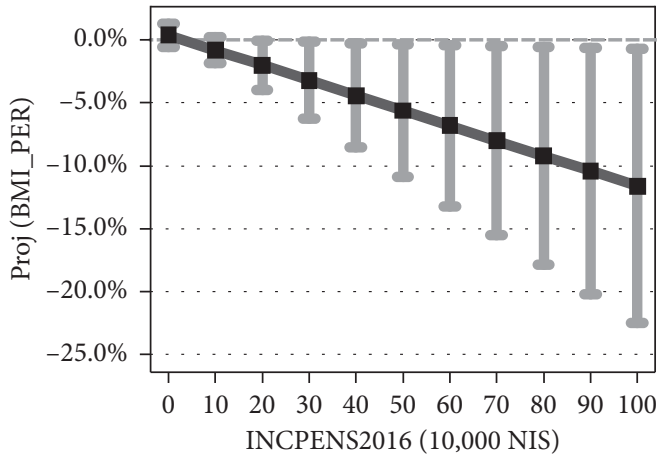

(a)

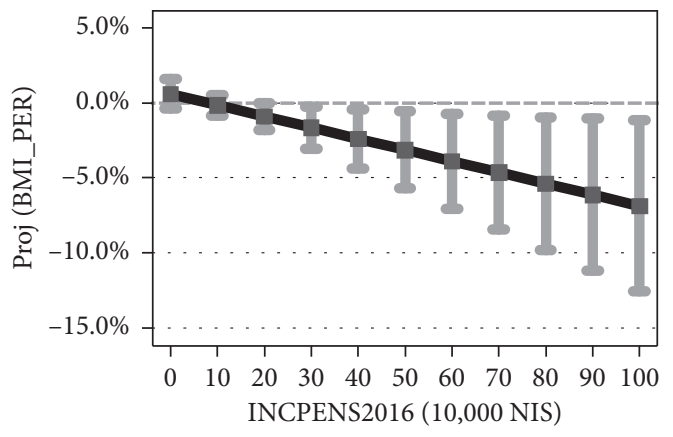

(c)

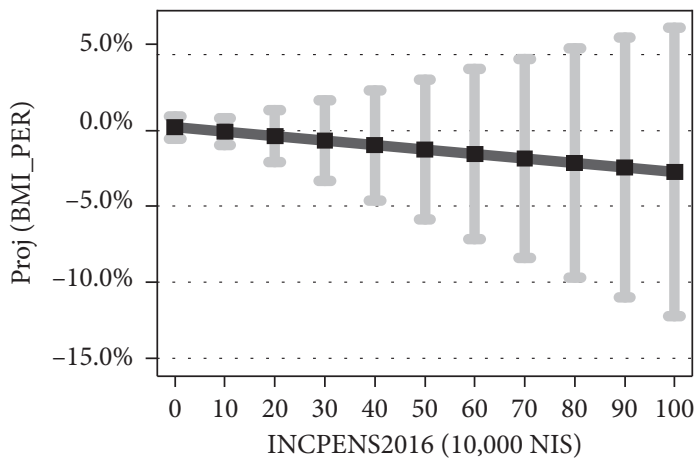

(b)

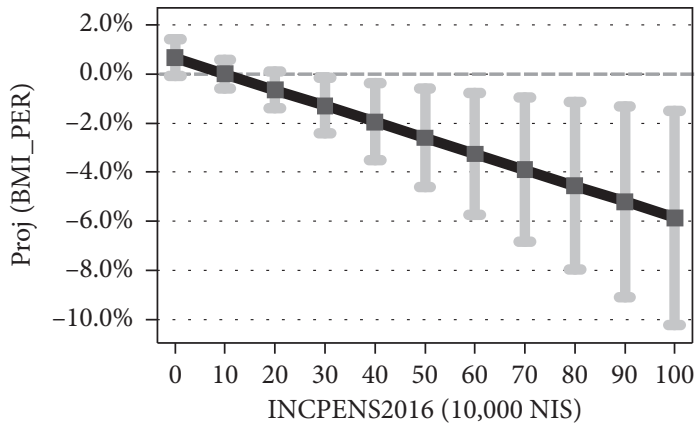

(d)

Figure 4: Percentage of BMI change across one year (2015-2016). Note. The figure is based on the regression outcomes available upon request based on the model given by equation (2). BMI_PER equals $100 \times$ [[BMI2016/BMI2015]-1]. (a) Women above 67 years. (b) Women above 62 years. (c) Men above 67 years. (d) Men above 62 years.

working-age population above 65 years is $21.1 \%$, compared with $27.9 \%$ in OECD countries [24].

Referring to the frequency of females $\times$ years vs. males $\times$ years in the sample for different cohorts, at the older cohort of Age $>67$, of the 1,771 respondents $\times$ years, females $\times$ years (males $\times$ years) consists of $52 \%(48 \%)$. The proportion of females $\times$ years is not different from $50 \%$ $(p=0.0916$ and $99 \%$ confidence interval of $[48.95 \%$, $55.06 \%])$. By comparison, at the younger cohorts of
$20<$ Age $\leq 67$, of the 9,329 respondents $\times$ year in the sample, the respective proportions drop (rise) to $50.49 \%$ $(49.51 \%)$ for females $\times$ years (males $\times$ years). Once again, the proportion of females $\times$ years is not different from $50 \%(p=0.3461$ and $99 \%$ confidence interval of [48.41\%, $50.57 \%]$ ). If the sample is representative, a possible interpretation is slightly lower (higher) mortality rates among females (males). It is also noteworthy that of the total population of adult respondents $\times$ year above 
TABLE 5: Numerical example: comparison between 2015 and 2016 BMI of women above 62 years. Consider the following example for women above 62 years (the same numbers that are described at the right-upper part of Figures 3 and 4).

\begin{tabular}{lcc}
\hline BMI2016 & 21.32663 \\
BMI2015 & 27.27488 & 21.9268070544 \\
(BMI2016/BMI2015) - & 27.2185830969 & $-2.737184 \%$ \\
Annual income from a pension & $0.2068326 \%$ & 1 million NIS \\
\hline
\end{tabular}

TABLE 6: Numerical example: comparison between 2015 and 2016 BMI of men above 62 years. Next, consider the following example for men above 62 years (the same numbers that are described at the right-lower parts of Figures 3 and 4).

\begin{tabular}{lcc}
\hline BMI2016 & 28.5859 \\
BMI2015 & 27.1695 & 30.3649305728 \\
(BMI2016/BMI2015) - & 26.9931164766 & $-5.858833 \%$ \\
Annual income from a pension & $0.6534389 \%$ & 0 NIS \\
\hline
\end{tabular}

TABLE 7: Descriptive statistics of 2015-2016 panel for women after retirement.

\begin{tabular}{|c|c|c|c|c|}
\hline Variables & Description & Obs. & Mean & $(\mathrm{SD})$ \\
\hline Weight & Weight in kg with light clothing without shoes & 921 & 69 & $(12.7)$ \\
\hline Height & Height in centimeters without shoes & 921 & 160 & $(6.3)$ \\
\hline BMI & Body mass $=10,000 \cdot($ Weight $/$ Height $)$ & 921 & 27 & $(4.9)$ \\
\hline BMI25 & $1=\mathrm{BMI} \geq 25 ; 0=\mathrm{BMI}<25$ & 921 & $65 \%$ & $(47.6 \%)$ \\
\hline BMI30 & $1=\mathrm{BMI} \geq 30 ; 0=\mathrm{BMI}<30$ & 921 & $23 \%$ & $(42.1 \%)$ \\
\hline BMI35 & $1=\mathrm{BMI} \geq 35 ; 0=\mathrm{BMI}<35$ & 921 & $8 \%$ & $(27.0 \%)$ \\
\hline GET_PENSION & $1=$ get pension; $0=$ otherwise & 921 & $40 \%$ & $(49.0 \%)$ \\
\hline INCPENS $>0$ & $\begin{array}{l}\text { Household's annual gross monetary income from a } \\
\text { pension in NIS for women who are either the } \\
\text { respondent or spouse in the household }\end{array}$ & 369 & 74,476 & $(76,904.0)$ \\
\hline Owner & $1=$ own an apartment; $0=$ otherwise & 921 & $75 \%$ & $(43.1 \%)$ \\
\hline Books & $\begin{array}{c}1=\text { At least one book at the home library; } 0=\text { no } \\
\text { books at the home library }\end{array}$ & 921 & $97 \%$ & $(16.6 \%)$ \\
\hline Car & $1=$ own a car; $0=$ otherwise & 921 & $46 \%$ & $(49.9 \%)$ \\
\hline Age & Age in years & 921 & 75 & $(4.4)$ \\
\hline Academic & $\begin{array}{c}1=\text { Formal academic education with BA, MA or } \\
\text { Ph.D. diploma; } 0=\text { otherwise }\end{array}$ & 921 & $30 \%$ & $(45.8 \%)$ \\
\hline HHSIZE & Number of persons in household & 921 & 2 & $(1.2)$ \\
\hline Single & $1=$ single $; 0=$ otherwise & 921 & $4 \%$ & $(19.4 \%)$ \\
\hline Married & $1=$ married $0=$ otherwise & 921 & $48 \%$ & $(50.0 \%)$ \\
\hline Divorced & $1=$ divorced $; 0=$ otherwise & 921 & $10 \%$ & $(30.3 \%)$ \\
\hline Widow & $1=$ widow $; 0=$ otherwise & 921 & $38 \%$ & $(48.6 \%)$ \\
\hline Immigrant & $1=$ immigrant $; 0=$ otherwise & 921 & $71 \%$ & $(45.2 \%)$ \\
\hline IMM_EUROPE_AMERICA & $\begin{array}{c}1=\text { immigrant from European or American } \\
\text { countries; } 0=\text { otherwise }\end{array}$ & 921 & $48 \%$ & $(50.0 \%)$ \\
\hline IMM_ASIA_AFRICA & $\begin{array}{l}1=\text { immigrant from Asian or African countries; } \\
\qquad 0=\text { otherwise }\end{array}$ & 921 & $23 \%$ & $(42.5 \%)$ \\
\hline IMM_EUROPE_AMERICA_PER & $\begin{array}{c}1=\text { immigrant from European or American countries } \\
\text { only for the group of immigrants; } 0=\text { otherwise }\end{array}$ & 657 & $67 \%$ & $(47.1 \%)$ \\
\hline OVERALL_HEALTH & $\begin{array}{l}1=\text { Self-reporting of good overall health conditions; } \\
\qquad 0=\text { otherwise }\end{array}$ & 921 & $48 \%$ & $(50.0 \%)$ \\
\hline
\end{tabular}

20 years, the respondents $\times$ year whose age is above 67 consists of $1,771 /(1,771+9,329) \approx 15.95 \%$. The equivalent national ratio for individuals whose age is above 65 years is $10.4 \%$ [28].

An acceptable measure of overweight is $\mathrm{BMI} \geq 25$ and obesity is $\mathrm{BMI} \geq 30$. As previously noted, BMI is Weight $\div\left(\right.$ Height $\left.^{2}\right)$ where Weight is measured in kilograms and Height is measured in meters. The sample mean BMI reported in Tables 7 and 8 is 26.992 (27.138) for females $\times$ years (males $\times$ years). Of the 921 (850) females $\times$ years (males $\times$ years), the frequency of $\mathrm{BMI} \geq 30$ is $23.0 \%$ (21.5\%). The $1.5 \%$ female-male difference has $p=0.4519$ (BMI30).

Figure 5 displays the proportions of obese females and males with $\mathrm{BMI} \geq 30$ for different cohorts. The figure demonstrates that obesity rises with age. As previously noted, among women (men) above 67 years, the frequency of obesity is $23.02 \%(21.53 \%)$. The $1.49 \%$ difference across gender has $p=0.4519$, where the $95 \%$ confidence interval is [-5.37\%, 2.39\%]. By comparison, among the women (men) for whom $20<$ Age $\leq 67$, the frequencies of obesity drop to 
TABLe 8: Descriptive statistics of 2015-2016 panel for men after retirement.

\begin{tabular}{|c|c|c|c|c|}
\hline Variables & Description & Obs. & Mean & $(\mathrm{SD})$ \\
\hline Weight & Weight in $\mathrm{kg}$ with light clothing and without shoes & 850 & 80 & $(13.5)$ \\
\hline Height & Height in meters without shoes & 850 & 171 & $(6.9)$ \\
\hline BMI & Body mass $=10,000 \cdot($ Weight $/$ Height $)$ & 850 & 27 & $(4.2)$ \\
\hline BMI25 & $1=\mathrm{BMI} \geq 25 ; 0=\mathrm{BMI}<25$ & 850 & $65 \%$ & $(47.6 \%)$ \\
\hline BMI30 & $1=\mathrm{BMI} \geq 30 ; 0=\mathrm{BMI}<30$ & 850 & $22 \%$ & $(41.1 \%)$ \\
\hline BMI35 & $1=\mathrm{BMI} \geq 35 ; 0=\mathrm{BMI}<35$ & 850 & $5 \%$ & $(20.7 \%)$ \\
\hline GET_PENSION & $1=$ receives pension; $0=$ otherwise & 850 & $38 \%$ & $(48.6 \%)$ \\
\hline INCPENS $>0$ & $\begin{array}{l}\text { Household's annual gross monetary income from } \\
\text { pensions in NIS for men who are either the } \\
\text { respondent or spouse in the household }\end{array}$ & 323 & 97,218 & $(102,324.0)$ \\
\hline Owner & $1=$ own an apartment; $0=$ otherwise & 850 & $73 \%$ & $(44.3 \%)$ \\
\hline Books & $\begin{array}{c}1=\text { At least one book at the home library; } 0=\text { no } \\
\text { books at the home library }\end{array}$ & 850 & $98 \%$ & $(14.0 \%)$ \\
\hline Car & $1=$ own a car; $0=$ otherwise & 850 & $65 \%$ & $(47.7 \%)$ \\
\hline Age & Age in years & 850 & 75 & $(4.5)$ \\
\hline Academic & $\begin{array}{c}1=\text { Formal academic education with BA, MA or } \\
\text { Ph.D. diploma; } 0=\text { otherwise }\end{array}$ & 850 & $34 \%$ & $(47.4 \%)$ \\
\hline HHSIZE & Number of persons in household & 850 & 2 & $(1.1)$ \\
\hline Single & $1=$ Single $; 0=$ otherwise & 850 & $2 \%$ & $(13.6 \%)$ \\
\hline Married & $1=$ Married $0=$ otherwise & 850 & $75 \%$ & $(43.3 \%)$ \\
\hline Divorced & $1=$ Divorced; $0=$ otherwise & 850 & $8 \%$ & $(27.7 \%)$ \\
\hline Widow & $1=$ Widow $0=$ otherwise & 850 & $15 \%$ & $(35.4 \%)$ \\
\hline Immigrant & $1=$ Immigrant; $0=$ otherwise & 850 & 0.696 & $(46.0 \%)$ \\
\hline IMM_EUROPE_AMERICA & $\begin{array}{l}1=\text { Immigrant from European or American } \\
\text { countries; } 0=\text { otherwise }\end{array}$ & 850 & $47 \%$ & $(49.9 \%)$ \\
\hline IMM_ASIA_AFRICA & $\begin{array}{c}1=\text { Immigrant from Asian or African countries; } \\
0=\text { otherwise }\end{array}$ & 850 & $23 \%$ & $(41.8 \%)$ \\
\hline IMM_EUROPE_AMERICA_PER & $\begin{array}{l}1=\text { Immigrant from European or American countries } \\
\text { only for the group of immigrants; } 0=\text { otherwise }\end{array}$ & 592 & $68 \%$ & $(46.9 \%)$ \\
\hline OVERALL_HEALTH & $\begin{array}{l}1=\text { Self-reporting of good overall health conditions; } \\
\qquad 0=\text { otherwise }\end{array}$ & 850 & $55 \%$ & $(49.8 \%)$ \\
\hline
\end{tabular}

Note. The sample includes panel of 921 (850) females $\times$ years (males $\times$ years) belonging to 507 (466) households, where the age of female (male) members were restricted to be above 67 years, participating in the 2015-2016 longitudinal survey carried out by the Israeli Central Bureau of Statistics. The lower age bound is based on the retirement age from the workforce, which is 67 years for males. NIS is the local Israeli currency, where 1 NIS roughly equals $\$ 0.25$. Standard deviations are given in parentheses.

$14.45 \%(16.32 \%)$. The $-1.87 \%$ difference across gender has $p=0.0145$, where the $95 \%$ confidence interval is $[-3.38 \%$, $-0.37 \%$. Finally, the rise of obesity by $8.57 \%(5.21 \%)$ with age for the group of females (males) has $p<0.001$.

Referring only to income from pensions, of the 921 (850) female (male) respondents above 67 year, $40.1 \%$ (38.0\%) receive pensions (GET_PENSION). By comparison to the national level, $46 \%$ of the elderly have pensions, and the income replacement ratio in Israel-the after-post pension income ratio-is only $55 \%-60 \%$ as compared to the average of $70 \%-80 \%$ in European countries [28] et al. The average annual pension of the 369 (323) female (male) respondents who receive pension is 74,476 NIS (97,218 NIS). The 22,742 NIS difference has $p=0.0011$, where the $99 \%$ confidence interval is $[4,757 ; 40,729]$ (INCPENS). Given that the average worker earning is 142,247 NIS ([24]), for the females (males) respondents, incomes from pensions consist of $52.36 \%(68.34 \%)$ of the average annual salary.

Figure 6 exhibits the relationship between the projected probability of obesity $(\mathrm{BMI} \geq 30)$ and annual gross income from a pension among females above 67 years. The projected probabilities were obtained from the probit model, where the dependent variable is BMI30 and the independent variable is INCPENS and refers to the $40.1 \%$ (59.9\%) of the 921 female respondents above 67 years who received a pension (without pension). The graph clearly indicates the drop in the projected probability of obesity from $27.27 \%$ for female respondents without pensions to about $3.93 \%$ for female respondents with annual income from a pension of 200,000 NIS (about $\$ 50,000$ ).

Tables 9 and 10 report the Pearson correlation matrix between the variables BMI30 INCPEN, Books, and Academic. For the female group, the Pearson correlation between BMI30 and INCPENS $(-13.55 \%)$ is negative and different from zero correlation $(p<0.0001)$. In contrast, the null hypothesis of zero correlation between BMI30 and INCPENS cannot be rejected for the 850 male respondents $(p=0.5680)$. The latter outcome implies that this drop with income is unique to females. No such drop is supported empirically among groups of males.

Referring to other wealth, income, and education variables in Tables 7 and 8, of the 921 (850) females $\times$ years (males $\times$ years), $75.4 \%(73.2 \%)$ live in a housing unit owned by the household (OWNER). By comparison, the national Israeli 2016 average shows that $67.6 \%$ are homeowners [29]. Of the 921 (850) females $\times$ years (males $\times$ years), $97.2 \%(98.0 \%)$ have at least one 


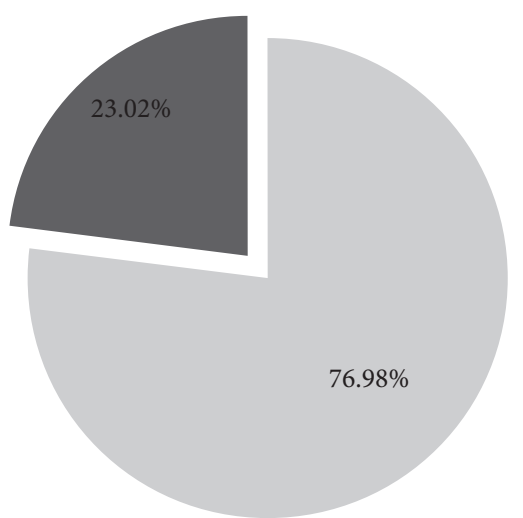

(a)

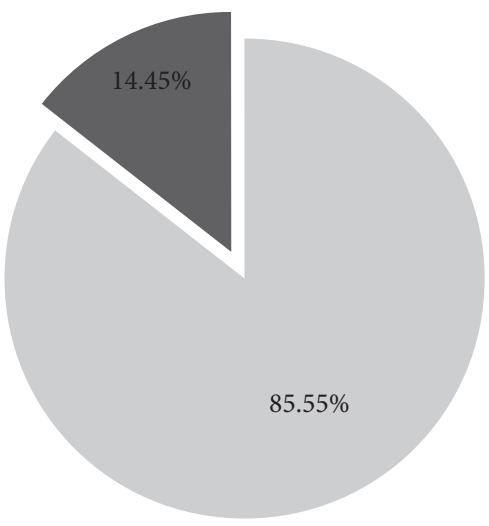

(c)

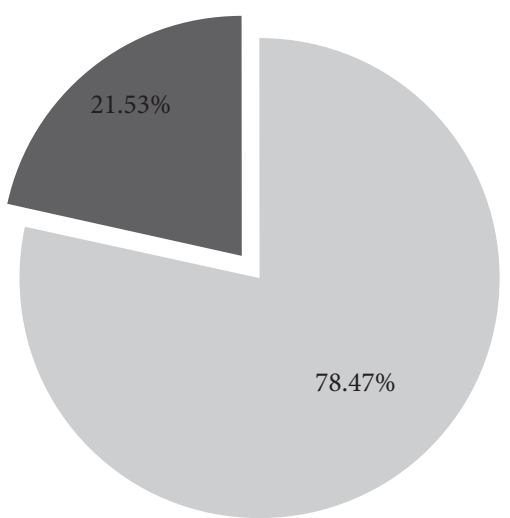

(b)

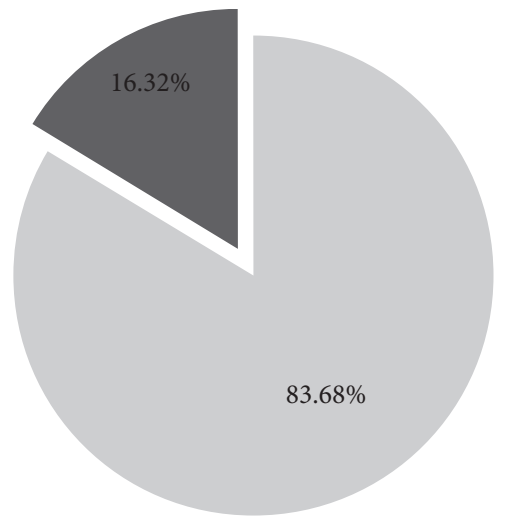

(d)

Figure 5: Proportion of obese females and males with $\mathrm{BMI} \geq 30$ for different cohorts. Note. The dark (bright) segment is the proportion of the sample with $\mathrm{BMI} \geq 30$ (BMI <30). (a) Females above 67 years. (b) Males above 67 years. (c) Females for whom $20<$ Age $\leq 67$ years. (d) Males for whom $20<$ Age $\leq 67$ years.

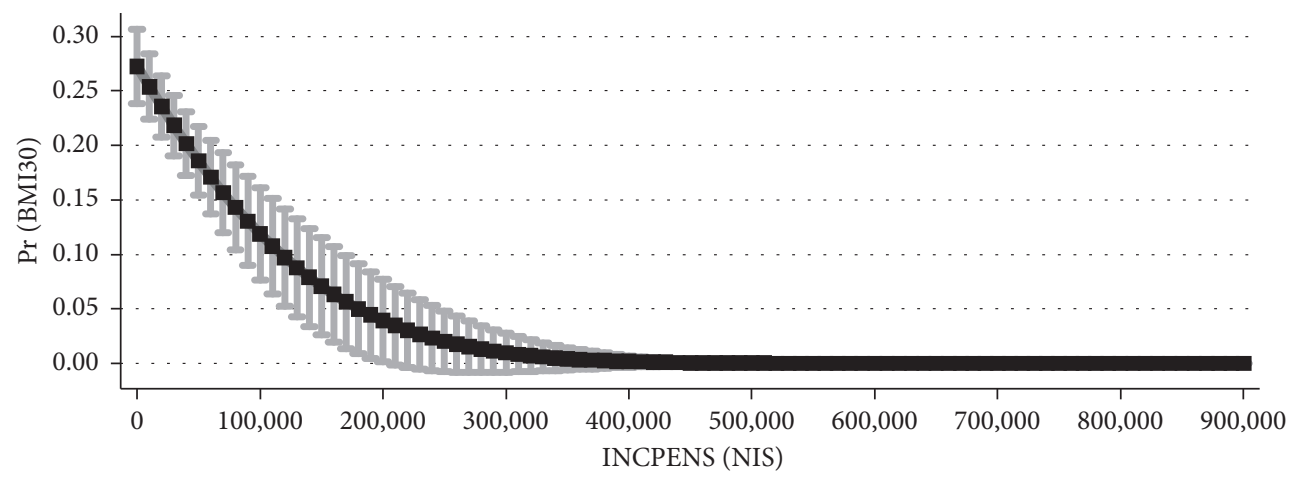

(a)

FIGURE 6: Continued. 


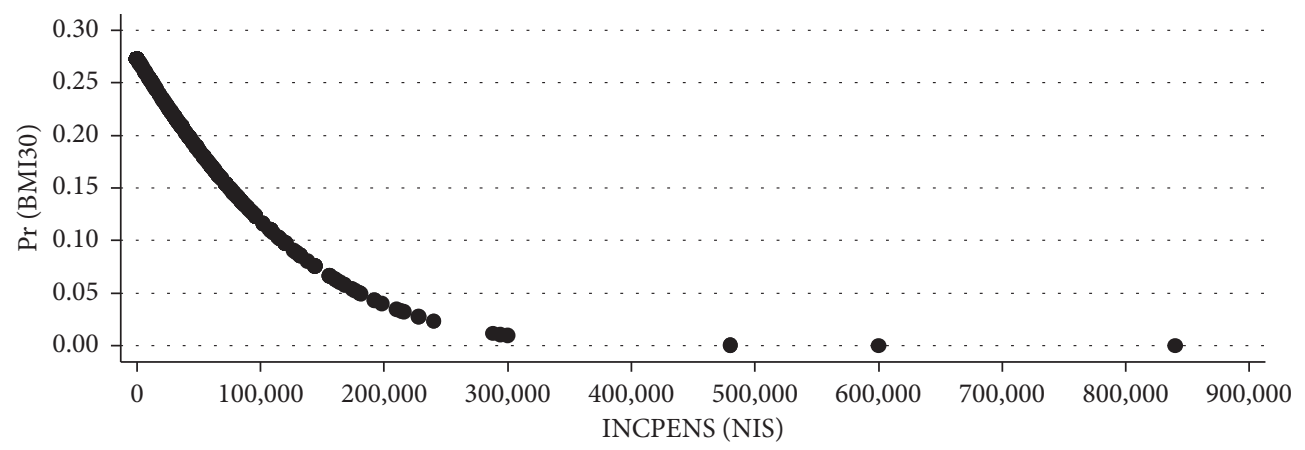

(b)

FIGURE 6: Relationship between projected probability of obesity (BMI $\geq 30)$ and annual gross income from a pension among females above 67 years. Note. The figure describes the projected probability obtained from the probit model, where the dependent variable is BMI30 and the independent variable is INCPENS, the annual gross monetary income from pensions measured in NIS, which refers to the $40.1 \%$ (59.9\%) of the 921 female respondents above 67 years who got pension (without pension). For the female group, the Pearson correlation between BMI30 and INCPENS $(-13.55 \%)$ is negative and different from zero correlation $(p<0.0001)$. In contrast, the null hypothesis of zero correlation between BMI30 and INCPENS cannot be rejected for the 850 male respondents $(p=0.5680)$.

TABLE 9: Pearson correlation matrix for females.

\begin{tabular}{lcccc}
\hline & BMI30 & INCPENS & Books & Academic \\
\hline BMI30 & 1.0000 & & & \\
& {$[921]$} & & & \\
INCPENS & $-0.1355^{* * *}$ & 1.0000 & & \\
& $(<0.0001)$ & & & \\
& {$[921]$} & {$[921]$} & & \\
Books & -0.0158 & 0.0571 & 1.0000 & \\
& $(0.6318)$ & $(0.1172)$ & & \\
& {$[921]$} & {$[921]$} & {$[921]$} & \\
Academic & $-0.0818^{* *}$ & $0.1750^{* * *}$ & $0.0829^{* *}$ & 1.0000 \\
& $(0.0130)$ & $(<0.0001)$ & $(0.0119)$ & \\
& {$[921]$} & {$[921]$} & {$[921]$} & {$[921]$} \\
\hline
\end{tabular}

TABle 10: Pearson correlation matrix for males.

\begin{tabular}{lcccc}
\hline & BMI30 & INCPENS & Books & Academic \\
\hline BMI30 & 1.0000 & & & \\
& {$[850]$} & & & \\
INCPENS & 0.0196 & 1.0000 & & \\
& $(0.5680)$ & & & \\
& {$[850]$} & {$[850]$} & & \\
Books & -0.0478 & 0.0339 & 1.0000 & \\
& $(0.1635)$ & $(0.3239)$ & & \\
& {$[850]$} & {$[850]$} & {$[850]$} & \\
Academic & $-0.1294^{* * *}$ & $0.1336^{* * *}$ & $0.0674^{* *}$ & 1.0000 \\
& $(0.0002)$ & $(0.0001)$ & $(0.0496)$ & \\
& {$[850]$} & {$[850]$} & {$[850]$} & {$[850]$} \\
\hline
\end{tabular}

Note. $p$ values are given in brackets. Number of observations is given in square brackets. ${ }^{* *} p<0.05$ and ${ }^{* * *} p<0.01$ for difference from zero correlation.

book in the home library (Books). 46.4\% (65.2\%) own a car (Car). By comparison, the national 2015 average shows that $69.7 \%$ of the 2.4139 million households own at least one car and $24.4 \%$ own two cars or more (Israeli CBS, [30]). Finally, 30\% $(34.2 \%)$ hold a BA, MA, or Ph.D. degree from academic institutions (Academic).
According to the reports in Tables 9 and 10, for females, BMI30 is negatively correlated with INCPENS, and this correlation is different from zero correlation $(p<0.0001)$. For both genders, BMI30 is negatively correlated with Academic $(p=0.0130$ for females and $p=0.0002$ for males). The implication is that the projected probability to become obese drops with academic education. For both genders, the Pearson correlations between INCPEN and Academic are all positive and different from zero correlation ( $p<0.0001$ for females and $p=0.0001$ for males). As expected, income from pensions rises with academic education.

Referring to the quantitative sociodemographic variables in Tables 7 and 8, the sample mean of the age variable is 74.64 for females and 74.66 for males. Given the imposed cutoff point, the minimum age for both genders is 68 years and the maximum age is 80 years (Age). By comparison, according to 2018 Statistical Abstract of Israel ([31]), the median age of the overall Israeli population is 31.0 years (29.8 years) for females (males). The number of household members is about two for both genders (HHSIZE).

Referring to the binary sociodemographic variables in Tables 7 and 8 , for the cohort of above 67 years, $3.90 \%$ (1.90\%) of the female (male) participants are single who were never married (Single), 47.7\% (75.1\%) are married (Married), $10.2 \%$ (8.4\%) are divorced (Divorced), and $38.2 \%(14.7 \%)$ are widowed (Widow). By comparison, according to the 2018 Statistical Abstract of Israel ([32]), the total Israeli population in 2016 includes 3.1317 (2.9987) million females (males), of whom $0.2451 \div 3.1317=7.826 \%$ $(0.0524 \div 2.9987=1.747 \%)$ are a widow (widower). Once again, the implication from these data might be that compared with females, mortality rates among males are higher. Indeed, the national statistics show that life expectancy of women is longer -84.2 years for females and 80.4 years for males (Israeli Central Bureau of Statistics Press Release, at [33]).

Finally, $71.3 \%(69.6 \%)$ are female (male) immigrants (Immigrants), of whom $47.7 \%(47.1 \%)$ are from European- 
American countries (IMM_EUROPE_AMERICA) and 23.7\% (22.6\%) from Asian-African countries (IMM_ASIA_AFRICA). These figures imply that $66.8 \%(67.6 \%)$ of the female (male) immigrants are from European-American countries (IMM_EUROPE_AMERICA_PER). By comparison, according to the 2018 Statistical Abstract of Israel, the proportion for the entire population of immigrants who emigrated to Israel in 1948-2017 in favor of European-American immigrants is $70.1 \%$ [34].

An interesting psychological feature in our sample is the self-assessment of overall health. Of the 921 (850) females $\times$ years (males $\times$ years), $48.4 \%$ (54.8\%) reported on good overall health. Stratification by cohorts show that compared with the adult group (Age $>67$ ), the report on good health among young respondents $(20<$ Age $\leq 67)$ rises by $36.99 \%, p<0.0001$ (32.13\%, $p<0.0001)$. Indeed, in the national level, compared with the younger cohorts, the self-assessment of health conditions among the older cohorts tends to be lower, and compared with women, the self-assessment of men tend to be higher [28].

4.2. The Empirical Model. Consider the following empirical model estimated separately for female and male respondents for the pooled sample:

$$
\begin{aligned}
\text { BMI30 }= & \gamma_{0}+\gamma_{1}\left(\text { INCPENS } \div\left(10^{4}\right)\right)+\gamma_{2} \text { OWNER } \\
& +\gamma_{3} \text { BOOKS }+\gamma_{4} \mathrm{CAR}+\gamma_{5} \mathrm{AGE} \\
& +\gamma_{6} \mathrm{ACADEMIC}+\gamma_{7} \mathrm{HHSIZE}+\gamma_{8} \text { MARRIED } \\
& +\gamma_{9} \mathrm{DIVORCED}+\gamma_{10} \text { WIDOW } \\
& +\gamma_{11} \text { IMM_EUROPE_AMERICA } \\
& +\gamma_{12} \text { IMM_ASIA_AFRICA } \\
& +\gamma_{13} \text { OVERALL_HEALTH }+D \vec{\delta}_{1}+\mu_{3},
\end{aligned}
$$

where BMI30, the dependent variable, is a dummy variable that equals 1 for obesity $(B M I \geq 30)$ and 0 otherwise. The independent variables include (1) wealth, income, and education proxies: INCPENS, Owner, Books, Car, and Academic; (2) quantitative sociodemographic characteristics: Age and HHSIZE; (3) family-status variables: Married, Divorced, and Widow (base category of Single); (4) immigration variables: IMM_EUROPE_AMERICA and IMM_ASIA_AFRICA (base category of Native Israeli); and (5) self-assessment of overall health OVERALL_HEALTH. $\alpha_{0}, \alpha_{1}, \ldots, \alpha_{13}$ are parameters, $D$ is a matrix of individual effect dummies, $\delta_{1}$ is a column vector of parameters, and $\mu_{1}$ is the stochastic random disturbance term.

4.3. Results. Table 11 reports the estimation results of the random effect panel regressions given by equation (3) among females and males above 67 years. The dependent variable is BMI30, a dummy variable that equals 1 for obesity, and 0 otherwise (BMI $\geq 30$ ). This Linear Probability
Model (LPM) yields projected probabilities of obesity; see the discussions in [35]: 415-418 and [36]: 727-730. Following the F-statistics, which reject the null hypothesis that the coefficients of individual effect dummies are equal, all the regressions include dummies Fixed-Effects, otherwise the coefficients might be inefficient (for a discussion see [35]: 391-395; [36]: 386-387). To correct for the inherent heteroskedasticity associated with the LPM, robust $p$ values are given in parentheses (for a discussion concerning robust standard errors see [35]: 162-166; 415-418; [36]: 428-429; 727-730). To provide the full information, the odd columns report the full model (e.g., $[25,26]$. The even columns report the stepwise model, which is obtained by gradual omission of variables with coefficients for whom $p<0.05$.

Results for women above 67 years indicate that the projected probability to become obese drops by $0.41 \%$ $(p=0.002)$ to $0.52 \%(p=0.001)$ with each additional 10,000 NIS to the annual gross pension. In contrast, for the male group above 67 years, regardless of the income level from a pension, the projected probability to become obese remains unchanged $(p=0.4225)$.

Referring to the female group above 67 years, and compared with married, divorced, and single women, the projected probability to become obese among widowed females above 67 years rises by $6.58 \%(p=0.0419)$ to $11.28 \%$ $(p=0.0048)$. The projected probability to become obese among divorced females above 67 years rises by $9.25 \%$ $(p=0.0319)$. Female respondents with a BA, MA, or Ph.D. degree are less likely to become obese by $6.23 \%(p=0.0966)$.

Referring to the male group above 67 years, the projected likelihood to become obese rises by $6.10 \%(p=0.0897)$ to $6.41 \%(p=0.0467)$ with ownership of at least one car. Male respondents with a $\mathrm{BA}, \mathrm{MA}$, or Ph.D. degree are less likely to become obese by $9.93 \%(p=0.0106)$ to $10.14 \%(p=0.0118)$. Finally, compared with native Israeli males, the projected odds to become obese drop by $7.67 \%(p=0.0821)$ to $8.99 \%$ $(p=0.0398)$ for male immigrants above 67 years from American-European countries. Compared with native Israeli males, the projected odds to become obese drop by $11.63 \%(p=0.0245)$ to $11.99 \%(p=0.02)$ for male immigrants above 67 years from Asian-African countries.

An interesting feature of our study is the self-ranking of overall health conditions. Results of our study demonstrate that for the female group above 67 years, compared with the base category-low self-ranking of health conditions-projected likelihood to become obese drops by $6.55 \%(p=0.0190)$ to $7.47 \%(p=0.0036)$ with self-ranking of good overall health conditions. In contrast, for the male group above 67 years, the coefficient of OVERALL_HEALTH is found to remain unchanged ( $p=0.2439)$.

4.4. Robustness Tests. Recently, Nyberg et al. [3] estimated the loss of disease-free years associated with class II-III obesity to range between 7.1 and 10.0 years in subgroups of participants of different socioeconomic levels, levels of physical activity, and smoking habits. In line with their study, we run a robustness test, which the cutoff point definition of obesity changes from $\mathrm{BMI} \geq 25$ (overweight) to 
TABLE 11: Random-Effect Regression 2015-2016: stratification by gender.

\begin{tabular}{|c|c|c|c|c|}
\hline Variables & $\begin{array}{c}\text { (1) } \\
\text { Full } \\
\text { BMI30 }\end{array}$ & $\begin{array}{c}(2) \\
\text { Stepwise } \\
\text { BMI30 }\end{array}$ & $\begin{array}{c}\text { (3) } \\
\text { Full } \\
\text { BMI30 }\end{array}$ & $\begin{array}{c}(4) \\
\text { Stepwise } \\
\text { BMI30 }\end{array}$ \\
\hline Constant & $\begin{array}{c}0.2245 \\
(0.4940)\end{array}$ & $\begin{array}{l}0.2528^{* * *} \\
(<0.0001)\end{array}$ & $\begin{array}{c}0.3330 \\
(0.3526)\end{array}$ & $\begin{array}{l}0.2715^{* * *} \\
(<0.0001)\end{array}$ \\
\hline INCPENS $\div\left(10^{4}\right)$ & $\begin{array}{c}-0.0041^{* * *} \\
(0.0021)\end{array}$ & $\begin{array}{c}-0.0052^{* * *} \\
(0.0001)\end{array}$ & $\begin{array}{c}0.0015 \\
(0.4225)\end{array}$ & $\begin{array}{l}- \\
-\end{array}$ \\
\hline Owner & $\begin{array}{c}0.0031 \\
(0.9375)\end{array}$ & - & $\begin{array}{l}-0.0342 \\
(0.3460)\end{array}$ & - \\
\hline Books & $\begin{array}{c}0.0806 \\
(0.2047)\end{array}$ & - & $\begin{array}{c}0.0013 \\
(0.9875)\end{array}$ & $\begin{array}{l}- \\
-\end{array}$ \\
\hline Car & $\begin{array}{l}-0.0460 \\
(0.1774)\end{array}$ & $\begin{array}{l}- \\
-\end{array}$ & $\begin{array}{l}0.0610^{*} \\
(0.0897)\end{array}$ & $\begin{array}{l}0.0641^{* *} \\
(0.0469)\end{array}$ \\
\hline Age & $\begin{array}{l}-0.0014 \\
(0.7353)\end{array}$ & $\begin{array}{l}- \\
-\end{array}$ & $\begin{array}{c}0.0003 \\
(0.9494)\end{array}$ & $\begin{array}{l}- \\
-\end{array}$ \\
\hline Academic & $\begin{array}{r}-0.0623^{*} \\
(0.0966)\end{array}$ & $\begin{array}{l}- \\
-\end{array}$ & $\begin{array}{c}-0.1014^{* *} \\
(0.0118)\end{array}$ & $\begin{array}{c}-0.0993^{* *} \\
(0.0106)\end{array}$ \\
\hline HHSIZE & $\begin{array}{c}0.0239 \\
(0.1549)\end{array}$ & $\begin{array}{l}- \\
-\end{array}$ & $\begin{array}{c}0.0059 \\
(0.7551)\end{array}$ & $\begin{array}{l}- \\
-\end{array}$ \\
\hline Married & $\begin{array}{c}0.0356 \\
(0.4045)\end{array}$ & $\begin{array}{l}- \\
-\end{array}$ & $\begin{array}{l}-0.0442 \\
(0.7685)\end{array}$ & $\begin{array}{l}- \\
-\end{array}$ \\
\hline Divorced & $\begin{array}{l}0.0925^{* *} \\
(0.0319)\end{array}$ & - & $\begin{array}{l}-0.1623 \\
(0.3060)\end{array}$ & - \\
\hline Widow & $\begin{array}{c}0.1128^{* * *} \\
(0.0048)\end{array}$ & $\begin{array}{l}0.0658^{* *} \\
(0.0419)\end{array}$ & $\begin{array}{l}-0.1004 \\
(0.5222)\end{array}$ & - \\
\hline IMM_EUROPE_AMERICA & $\begin{array}{c}0.0162 \\
(0.7047)\end{array}$ & - & $\begin{array}{c}-0.0767^{*} \\
(0.0821)\end{array}$ & $\begin{array}{c}-0.0899^{* *} \\
(0.0398)\end{array}$ \\
\hline IMM_ASIA_AFRICA & $\begin{array}{l}-0.0544 \\
(0.2377)\end{array}$ & - & $\begin{array}{c}-0.1163^{* *} \\
(0.0245)\end{array}$ & $\begin{array}{c}-0.1199^{* *} \\
(0.0200)\end{array}$ \\
\hline OVERALL_HEALTH & $\begin{array}{c}-0.0655^{* *} \\
(0.0190)\end{array}$ & $\begin{array}{c}-0.0747^{* * *} \\
(0.0036)\end{array}$ & $\begin{array}{l}-0.0345 \\
(0.2439)\end{array}$ & - \\
\hline Gender & Females & Females & Males & Males \\
\hline Age & Above 67 & Above 67 & Above 67 & Above 67 \\
\hline Observations & 921 & 921 & 850 & 850 \\
\hline R-squared & 0.0569 & 0.0370 & 0.0560 & 0.0370 \\
\hline Households & 507 & 507 & 466 & 466 \\
\hline Wald chi $^{2}$ : all coef. equals zero & $47.25^{* * *}$ & $28.59^{* * *}$ & $25.09^{* * *}$ & $19.67^{* * *}$ \\
\hline Individual effect F-Statistics & $6.79^{* * *}$ & $6.98^{* * *}$ & $4.58^{* * *}$ & $4.69^{* * *}$ \\
\hline Variance inflating factor (VIF) & 2.34 & 1.07 & 2.78 & 1.25 \\
\hline
\end{tabular}

Note. The table reports the estimation results of equation (3) for the group of retired women and men estimated via the random effect regression. The results of individual-effect F-statistics justify this procedure, which includes the individual effect dummies. The dependent variable is BMI30, a dummy variable, which equals one for Type I obesity (BMI $\geq 30$ ) and zero otherwise. The stepwise procedure gradually omits variables with coefficients for whom $p \geq 0.05$. Variance inflation factor (VIF) is a measure for collinearity among independent variables. VIF $<10$ implies low collinearity. Robust $p$ values are given in parentheses. ${ }^{*} p<0.1$. ${ }^{* *} p<0.05 .{ }^{* * *} p<0.01$.

$\mathrm{BMI} \geq 30$ (type I obesity) to $\mathrm{BMI} \geq 35$ (type II obesity). Table 7 shows that, as expected, as the benchmark changes from BMI25 to BMI30 and to BMI35, the relative frequency of females $\times$ years above this benchmark drops from $65.4 \%$ to $23.0 \%$ to $7.9 \%$. The equivalent frequencies of males $\times$ years are $65.4 \%$ to $21.5 \%$ to $4.5 \%$ (Table 8 ).

Figure 7 describes the projected probabilities obtained from the probit model, where the dependent variables are BMI25, BMI30, BMI35, and dummy variables, which equal one for Overweight $(\mathrm{BMI} \geq 25)$ and Type $\mathrm{I}(\mathrm{BMI} \geq 30)$ and Type II Obesity $(B M I \geq 35)$ and zero otherwise. The independent variable is INCPENS, the annual gross monetary income from a pension measured in NIS (the local Israeli currency, 1 NIS $\approx \$ 0.25$ ), which refers to the $40.1 \%$ (59.9\%) of the 921 female respondents above 67 years who got a pension (without pension). We excluded a few outliers for which INCPES $>250,000$.

As the figure shows, for women, all three benchmarks of obesity exhibit a drop with INCPENS. However, an increase in the benchmark from BMI25 to BMI30 to BMI35 attenuates this drop. For women, the respective Pearson correlations between BMI25, BMI30, BMI35, and INCPENS $(-13.90 \%,-13.55 \%,-10.01 \%)$ are negative and different from zero correlation $(p<0.0001, p<0.0001$, and $p=0.0024$, respectively). The Pearson correlations between BMI25, BMI30, BMI35, and INCPENS among the 869 male respondents were found to be equal to zero $(p=0.5016$, $p=0.5680$ and $p=0.0530$, respectively).

Table 12 presents the Random-Effect Regression 20152016: stratification by Overweight $(\mathrm{BMI} \geq 25)$, Type I 


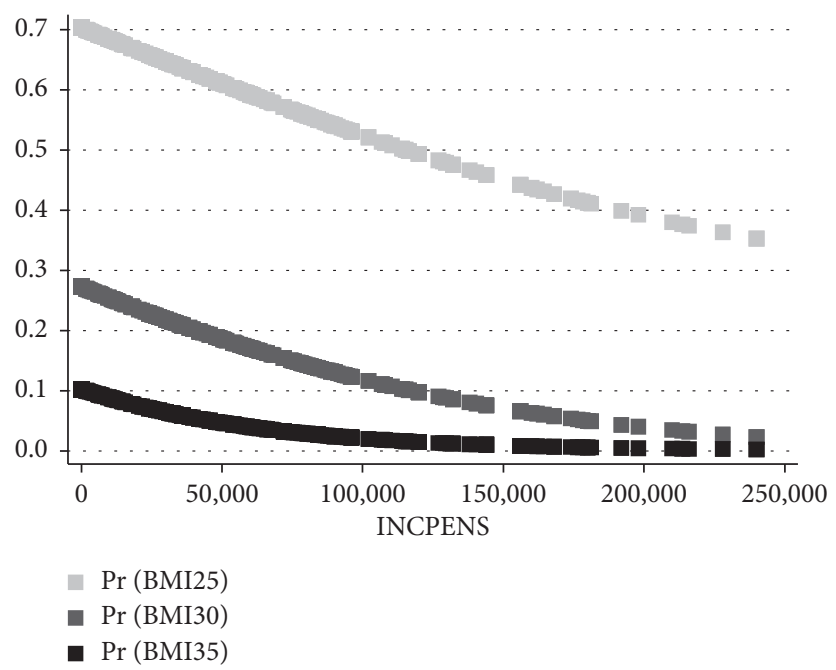

FIgURE 7: Relationship between the projected probability of Overweight (BMI $\geq 25$ ), Type I (BMI $\geq 30$ ), and Type II obesity (BMI $\geq 35$ ) and annual gross income from pension among females above 67 years. Note. The figure describes the projected probabilities obtained from the probit model, where the dependent variables are BMI25, BMI30, BMI35, dummy variables, which equal one for Overweight (BMI $\geq 25$ ), Type I $(\mathrm{BMI} \geq 30)$, and Type II obesity (BMI $\geq 35)$ and zero otherwise. The independent variable is INCPENS, the annual gross monetary income from pensions measured in NIS (the local Israeli currency, 1 NIS $\approx \$ 0.25$ ), which refers to the $40.1 \%$ (59.9\%) of the 921 female respondents above 67 years who got pension (without pension). We excluded a few outliers for which INCPES $>250,000$. For women, the respective Pearson correlations between BMI25, BMI30, BMI35, and INCPENS $(-13.90 \%,-13.55 \%,-10.01 \%)$ are negative and different from zero correlation $(p<0.0001, p<0.0001$, and $p=0.0024$, respectively). The Pearson correlations between BMI25, BMI30, BMI35, and INCPENS among the 869 male respondents were found to be equal to zero ( $p=0.5016, p=0.5680$, and $p=0.0530$, respectively).

TABLE 12: Random-Effect Regression 2015-2016: stratification by Overweight (BMI $\geq 25$ ), Type I (BMI $\geq 30$ ), and Type II (BMI $\geq 35$ ) obesity among females above 67 years.

\begin{tabular}{|c|c|c|c|c|c|c|}
\hline Variables & $\begin{array}{c}(1) \\
\text { Full } \\
\text { BMI25 }\end{array}$ & $\begin{array}{c}(2) \\
\text { Stepwise } \\
\text { BMI25 }\end{array}$ & $\begin{array}{c}(3) \\
\text { Full } \\
\text { BMI30 }\end{array}$ & $\begin{array}{c}(4) \\
\text { Stepwise } \\
\text { BMI30 }\end{array}$ & $\begin{array}{c}(5) \\
\text { Full } \\
\text { BMI35 }\end{array}$ & $\begin{array}{c}(6) \\
\text { Stepwise } \\
\text { BMI35 }\end{array}$ \\
\hline Constant & $\begin{array}{c}1.0562^{* * *} \\
(0.0036)\end{array}$ & $\begin{array}{l}0.7178^{* * *} \\
(<0.0001)\end{array}$ & $\begin{array}{c}0.2245 \\
(0.4940)\end{array}$ & $\begin{array}{l}0.2528^{* * *} \\
(<0.0001)\end{array}$ & $\begin{array}{c}0.0900 \\
(0.6601)\end{array}$ & $\begin{array}{l}-0.0373 \\
(0.3270)\end{array}$ \\
\hline INCPENS $\div\left(10^{4}\right)$ & $\begin{array}{c}-0.0084^{* * *} \\
(0.0056)\end{array}$ & $\begin{array}{c}-0.0095^{* * *} \\
(0.0014)\end{array}$ & $\begin{array}{l}-0.0041^{* * *} \\
(0.0021)\end{array}$ & $\begin{array}{c}-0.0052^{* * * *} \\
(0.0001)\end{array}$ & $\begin{array}{l}-0.0015 \\
(0.1699)\end{array}$ & $\begin{array}{l}- \\
-\end{array}$ \\
\hline Owner & $\begin{array}{l}-0.0538 \\
(0.2784)\end{array}$ & - & $\begin{array}{c}0.0031 \\
(0.9375)\end{array}$ & $\begin{array}{l}- \\
-\end{array}$ & $\begin{array}{l}0.0414^{* *} \\
(0.0169)\end{array}$ & $\begin{array}{c}0.0437^{* * *} \\
(0.0089)\end{array}$ \\
\hline Books & $\begin{array}{l}-0.0471 \\
(0.5753)\end{array}$ & $\begin{array}{l}- \\
-\end{array}$ & $\begin{array}{c}0.0806 \\
(0.2047)\end{array}$ & $\begin{array}{l}- \\
-\end{array}$ & $\begin{array}{l}-0.0287 \\
(0.3613)\end{array}$ & - \\
\hline Car & $\begin{array}{l}-0.0436 \\
(0.3183)\end{array}$ & $\begin{array}{l}- \\
-\end{array}$ & $\begin{array}{l}-0.0460 \\
(0.1774)\end{array}$ & $\begin{array}{l}- \\
-\end{array}$ & $\begin{array}{l}-0.0240 \\
(0.2806)\end{array}$ & - \\
\hline Age & $\begin{array}{l}-0.0033 \\
(0.4729)\end{array}$ & $\begin{array}{l}- \\
-\end{array}$ & $\begin{array}{l}-0.0014 \\
(0.7353)\end{array}$ & $\begin{array}{l}- \\
-\end{array}$ & $\begin{array}{l}-0.0014 \\
(0.5709)\end{array}$ & - \\
\hline Academic & $\begin{array}{l}-0.0204 \\
(0.6753)\end{array}$ & $\begin{array}{l}- \\
-\end{array}$ & $\begin{array}{l}-0.0623^{*} \\
(0.0966)\end{array}$ & $\begin{array}{l}- \\
-\end{array}$ & $\begin{array}{c}0.0038 \\
(0.8731)\end{array}$ & - \\
\hline HHSIZE & $\begin{array}{l}0.0231^{*} \\
(0.0840)\end{array}$ & $\begin{array}{l}- \\
-\end{array}$ & $\begin{array}{c}0.0239 \\
(0.1549)\end{array}$ & $\begin{array}{l}- \\
-\end{array}$ & $\begin{array}{l}0.0357^{* *} \\
(0.0211)\end{array}$ & $\begin{array}{c}0.0353^{* *} \\
(0.0201)\end{array}$ \\
\hline Married & $\begin{array}{l}-0.0388 \\
(0.7169)\end{array}$ & $\begin{array}{l}- \\
-\end{array}$ & $\begin{array}{c}0.0356 \\
(0.4045)\end{array}$ & $\begin{array}{l}- \\
-\end{array}$ & $\begin{array}{c}0.0433 \\
(0.3494)\end{array}$ & $\begin{array}{l}- \\
-\end{array}$ \\
\hline Divorced & $\begin{array}{l}-0.1029 \\
(0.4013)\end{array}$ & $\begin{array}{l}- \\
-\end{array}$ & $\begin{array}{l}0.0925^{* *} \\
(0.0319)\end{array}$ & $\begin{array}{l}- \\
-\end{array}$ & $\begin{array}{l}0.1244^{*} \\
(0.0572)\end{array}$ & $\begin{array}{l}0.0983^{* *} \\
(0.0340)\end{array}$ \\
\hline Widow & $\begin{array}{l}-0.0277 \\
(0.7978)\end{array}$ & $\begin{array}{l}- \\
-\end{array}$ & $\begin{array}{c}0.1128^{* * *} \\
(0.0048)\end{array}$ & $\begin{array}{l}0.0658^{* *} \\
(0.0419)\end{array}$ & $\begin{array}{l}0.0906^{* *} \\
(0.0430)\end{array}$ & $\begin{array}{l}0.0531^{* *} \\
(0.0377)\end{array}$ \\
\hline IMM_EUROPE_AMERICA & $\begin{array}{c}0.0406 \\
(0.4103)\end{array}$ & - & $\begin{array}{c}0.0162 \\
(0.7047)\end{array}$ & $\begin{array}{l}- \\
-\end{array}$ & $\begin{array}{l}-0.0184 \\
(0.5098)\end{array}$ & $\begin{array}{l}- \\
-\end{array}$ \\
\hline IMM_ASIA_AFRICA & $\begin{array}{l}-0.0468 \\
(0.4070)\end{array}$ & - & $\begin{array}{l}-0.0544 \\
(0.2377)\end{array}$ & - & $\begin{array}{l}-0.0379 \\
(0.1886)\end{array}$ & - \\
\hline OVERALL_HEALTH & $\begin{array}{c}-0.0535^{*} \\
(0.0792)\end{array}$ & $\begin{array}{c}-0.0632^{* *} \\
(0.0275)\end{array}$ & $\begin{array}{c}-0.0655^{* *} \\
(0.0190)\end{array}$ & $\begin{array}{c}-0.0747^{* * *} \\
(0.0036)\end{array}$ & $\begin{array}{r}-0.0245^{*} \\
(0.0721)\end{array}$ & $\begin{array}{c}-0.0282^{* *} \\
(0.0288)\end{array}$ \\
\hline
\end{tabular}


TABle 12: Continued.

\begin{tabular}{|c|c|c|c|c|c|c|}
\hline Variables & $\begin{array}{c}\text { (1) } \\
\text { Full } \\
\text { BMI25 } \\
\end{array}$ & $\begin{array}{c}(2) \\
\text { Stepwise } \\
\text { BMI25 }\end{array}$ & $\begin{array}{c}(3) \\
\text { Full } \\
\text { BMI30 } \\
\end{array}$ & $\begin{array}{c}(4) \\
\text { Stepwise } \\
\text { BMI30 }\end{array}$ & $\begin{array}{c}(5) \\
\text { Full } \\
\text { BMI35 } \\
\end{array}$ & $\begin{array}{c}\text { (6) } \\
\text { Stepwise } \\
\text { BMI35 }\end{array}$ \\
\hline Gender & Female & Female & Females & Females & Female & Female \\
\hline Age & Above 67 & Above 67 & Above 67 & Above 67 & Above 67 & Above 67 \\
\hline Observations & 921 & 921 & 921 & 921 & 921 & 921 \\
\hline R-squared & 0.0485 & 0.0385 & 0.0569 & 0.0370 & 0.0853 & 0.0761 \\
\hline Households & 507 & 507 & 507 & 507 & 507 & 507 \\
\hline Wald chi ${ }^{2}$ : all coef. equals zero & $27.53^{* * *}$ & $17.73^{* * *}$ & $47.25^{* * *}$ & $28.59^{* * *}$ & $25.54^{* * *}$ & $19.41^{* * *}$ \\
\hline Individual effect F-Statistics & $5.54^{* * *}$ & $5.55^{* * *}$ & $6.79^{* * *}$ & $6.98^{* * *}$ & $6.79^{* * *}$ & $6.51^{* * *}$ \\
\hline Variance inflation factor (VIF) & 2.34 & 1.06 & 2.34 & 1.07 & 2.34 & 1.10 \\
\hline
\end{tabular}

Note. The table reports the estimation results of equation (3) for the group of retired women estimated via the random effect regression. The results of individual-effect F-statistics justify this procedure, which includes the individual effect dummies of households. The dependent variables are BMI25, BMI30, BMI35, and dummy variables, which equal one for Overweight (BMI $\geq 25)$, Type I (BMI $\geq 30$ ), and Type II Obesity (BMI $\geq 35$ ) and zero otherwise. The stepwise procedure gradually omits variables with coefficients for whom $p<0.05$. Variance inflation factor (VIF) is a measure for collinearity among independent variables. VIF $<10$ implies low collinearity. Robust $p$ values are given in parentheses. ${ }^{*} p<0.1 .{ }^{* *} p<0.05 .{ }^{* * *} p<0.01$.

TABLE 13: Random-Effect Regression 2015-2016: stratification by Overweight (BMI $\geq 25$ ), Type I (BMI $\geq 30$ ), and Type II (BMI $\geq 35$ ) obesity among males above 67 years.

\begin{tabular}{|c|c|c|c|c|c|c|}
\hline Variables & $\begin{array}{c}(1) \\
\text { Full } \\
\text { BMI25 } \\
\end{array}$ & $\begin{array}{c}(2) \\
\text { Stepwise } \\
\text { BMI25 }\end{array}$ & $\begin{array}{c}\text { (3) } \\
\text { Full } \\
\text { BMI30 }\end{array}$ & $\begin{array}{c}(4) \\
\text { Stepwise } \\
\text { BMI30 }\end{array}$ & $\begin{array}{c}(5) \\
\text { Full } \\
\text { BMI35 } \\
\end{array}$ & $\begin{array}{c}\text { (6) } \\
\text { Stepwise } \\
\text { BMI35 }\end{array}$ \\
\hline Constant & $\begin{array}{c}1.4435^{* * *} \\
(0.0002)\end{array}$ & $\begin{array}{c}1.3911^{* * *} \\
(0.0001)\end{array}$ & $\begin{array}{c}0.3330 \\
(0.3526)\end{array}$ & $\begin{array}{l}0.2715^{* * *} \\
(<0.0001)\end{array}$ & $\begin{array}{c}0.0424 \\
(0.8479)\end{array}$ & $\begin{array}{c}0.0256^{* * *} \\
(0.0088)\end{array}$ \\
\hline INCPENS $\div\left(10^{5}\right)$ & $\begin{array}{c}0.0018 \\
(0.4404)\end{array}$ & - & $\begin{array}{c}0.0015 \\
(0.4225)\end{array}$ & $\begin{array}{l}- \\
-\end{array}$ & $\begin{array}{c}0.0005 \\
(0.5758)\end{array}$ & $\begin{array}{l}- \\
-\end{array}$ \\
\hline Owner & $\begin{array}{c}0.0025 \\
(0.9489)\end{array}$ & - & $\begin{array}{l}-0.0342 \\
(0.3460)\end{array}$ & $\begin{array}{l}- \\
-\end{array}$ & $\begin{array}{c}0.0274^{* *} \\
(0.0400)\end{array}$ & $\begin{array}{c}0.0255^{* *} \\
(0.0431)\end{array}$ \\
\hline Books & $\begin{array}{l}-0.0535 \\
(0.1509)\end{array}$ & - & $\begin{array}{c}0.0013 \\
(0.9875)\end{array}$ & - & $\begin{array}{c}0.0467 \\
(0.5461)\end{array}$ & $\begin{array}{l}- \\
-\end{array}$ \\
\hline Car & $\begin{array}{c}0.0050 \\
(0.8735)\end{array}$ & - & $\begin{array}{l}0.0610^{*} \\
(0.0897)\end{array}$ & $\begin{array}{c}0.0641^{* *} \\
(0.0469)\end{array}$ & $\begin{array}{c}0.0074 \\
(0.4648)\end{array}$ & - \\
\hline Age & $\begin{array}{c}-0.0103^{* *} \\
(0.0328)\end{array}$ & $\begin{array}{c}-0.0099^{* *} \\
(0.0450)\end{array}$ & $\begin{array}{c}0.0003 \\
(0.9494)\end{array}$ & $\begin{array}{l}- \\
-\end{array}$ & $\begin{array}{l}-0.0004 \\
(0.8297)\end{array}$ & - \\
\hline Academic & $\begin{array}{l}-0.0579 \\
(0.2690)\end{array}$ & $\begin{array}{l}- \\
-\end{array}$ & $\begin{array}{c}-0.1014^{* *} \\
(0.0118)\end{array}$ & $\begin{array}{c}-0.0993^{* *} \\
(0.0106)\end{array}$ & $\begin{array}{c}0.0225 \\
(0.6095)\end{array}$ & - \\
\hline HHSIZE & $\begin{array}{c}0.0051 \\
(0.7859)\end{array}$ & - & $\begin{array}{c}0.0059 \\
(0.7551)\end{array}$ & - & $\begin{array}{c}0.0101 \\
(0.4697)\end{array}$ & - \\
\hline Married & $\begin{array}{c}0.0126 \\
(0.9057)\end{array}$ & - & $\begin{array}{l}-0.0442 \\
(0.7685)\end{array}$ & - & $\begin{array}{l}-0.0489 \\
(0.3894)\end{array}$ & - \\
\hline Divorced & $\begin{array}{l}-0.0515 \\
(0.6554)\end{array}$ & - & $\begin{array}{l}-0.1623 \\
(0.3060)\end{array}$ & - & $\begin{array}{l}-0.0538 \\
(0.3428)\end{array}$ & - \\
\hline Widow & $\begin{array}{l}-0.0101 \\
(0.9233)\end{array}$ & - & $\begin{array}{l}-0.1004 \\
(0.5222)\end{array}$ & - & $\begin{array}{l}-0.0504 \\
(0.3341)\end{array}$ & - \\
\hline IMM_EUROPE_AMERICA & $\begin{array}{c}0.0718 \\
(0.1637)\end{array}$ & - & $\begin{array}{c}-0.0767^{*} \\
(0.0821)\end{array}$ & $\begin{array}{c}-0.0899^{* *} \\
(0.0398)\end{array}$ & $\begin{array}{l}-0.0197 \\
(0.4167)\end{array}$ & - \\
\hline IMM_ASIA_AFRICA & $\begin{array}{l}-0.0450 \\
(0.4567)\end{array}$ & - & $\begin{array}{c}-0.1163^{* *} \\
(0.0245)\end{array}$ & $\begin{array}{c}-0.1199^{* *} \\
(0.0200)\end{array}$ & $\begin{array}{l}-0.0036 \\
(0.8975)\end{array}$ & - \\
\hline OVERALL_HEALTH & $\begin{array}{c}0.0027 \\
(0.9232)\end{array}$ & - & $\begin{array}{l}-0.0345 \\
(0.2439)\end{array}$ & - & $\begin{array}{l}-0.0164 \\
(0.3300)\end{array}$ & - \\
\hline Gender & Males & Males & Males & Males & Males & Males \\
\hline Age & Above 67 & Above 67 & Above 67 & Above 67 & Above 67 & Above 67 \\
\hline Observations & 850 & 850 & 850 & 850 & 850 & 850 \\
\hline R-squared & 0.0255 & 0.00900 & 0.0560 & 0.0370 & 0.0157 & 0.00573 \\
\hline Households & 466 & 466 & 466 & 466 & 466 & 466 \\
\hline Wald chi ${ }^{2}$ : all coef. equals zero & 13.48 & $4.020^{* *}$ & $25.09^{* * *}$ & $19.67^{* * *}$ & 8.487 & $4.091^{* *}$ \\
\hline
\end{tabular}


TABle 13: Continued.

\begin{tabular}{|c|c|c|c|c|c|c|}
\hline Variables & $\begin{array}{c}\text { (1) } \\
\text { Full } \\
\text { BMI25 }\end{array}$ & $\begin{array}{c}(2) \\
\text { Stepwise } \\
\text { BMI25 }\end{array}$ & $\begin{array}{c}\text { (3) } \\
\text { Full } \\
\text { BMI30 }\end{array}$ & $\begin{array}{c}(4) \\
\text { Stepwise } \\
\text { BMI30 }\end{array}$ & $\begin{array}{c}\text { (5) } \\
\text { Full } \\
\text { BMI35 }\end{array}$ & $\begin{array}{c}\text { (6) } \\
\text { Stepwise } \\
\text { BMI35 }\end{array}$ \\
\hline Individual effect F-Statistics & $7.13^{* * *}$ & $7.07^{* * *}$ & $4.58^{* * *}$ & $4.69^{* * *}$ & $13.38^{* * *}$ & $11.06^{* * *}$ \\
\hline Variance inflation factor (VIF) & 2.78 & 1.00 & 2.78 & 1.25 & 2.78 & 1.00 \\
\hline
\end{tabular}

Note. The table reports the estimation results of equation (3) for the group of retired men estimated via the random effect regression. The results of individualeffect F-statistics justify this procedure, which includes the individual effect dummies of households. The dependent variables are BMI25, BMI30, BMI35, and dummy variables, which equal one for Overweight (BMI $\geq 25)$, Type I (BMI $\geq 30$ ), and Type II Obesity (BMI $\geq 35)$ and zero otherwise. The stepwise procedure gradually omits variables with coefficients for whom $p<0.05$. Variance inflation factor (VIF) is a measure for collinearity among independent variables. $\mathrm{VIF}<10$ implies low collinearity. Robust $p$ values are given in parentheses. ${ }^{*} p<0.1 .{ }^{* *} p<0.05 .{ }^{* * *} p<0.01$.

(BMI $\geq 30)$, and Type II (BMI $\geq 35)$ obesity among females above 67 years. The empirical model is based on equation (3), where the dependent variable is replaced from BMI25 to BMI30 and to BMI35. Once again, to provide the full information, the odd columns report the full model (e.g., $[25,26])$. The even columns report the stepwise model, which is obtained by gradual omission of variables with coefficients for whom $p>0.05$.

Results indicate that the projected probability of overweight among retired female respondents drops by $0.84 \%$ ( $p=0.0056)$ to $0.95 \%(p=0.0014)$ with each additional 10,000 NIS annual gross monetary income from a pension. This drop attenuates to $0.41 \%(p=0.0021)$ to $0.52 \%$ $(p=0.0001)$ for type I obesity. The projected probability of type II obesity remains unchanged with the annual level of monetary income from a pension $(p=0.1699)$.

Interestingly, narrowing the benchmark to type II obesity among retired women modifies the coefficient of Owner to positive. The projected probability of type II obesity rises with homeownership by $4.14 \%(p=0.0169)$ to $4.37 \%(p=0.0089)$. An additional variable whose coefficient becomes positive is HHSIZE, where the projected probability of type II obesity rises by $3.53 \%(p=0.0201)$ to $3.57 \%$ ( $p=0.0211$ ) with each additional person in the household. The projected probability of type II obesity among retired women rises by $9.83 \%(p=0.0340)$ to $12.44 \%(p=0.0572)$ with family status of divorced and by $5.31 \%(p=0.0377)$ to $9.06 \%(p=0.0430)$ with family status of widow. Finally, the sign of the coefficient of OVERALL_HEALTH remains robust where the definition of obesity becomes narrower. The projected probabilities of overweight and type I and type II obesity among retired women drop by $2.45 \%(p=0.0721)$ to $7.47 \%(p=0.0036)$ with self-report of overall good health conditions.

To simplify the comparison, Table 13 presents the Random-Effect Regression 2015-2016: stratification by Overweight (BMI $\geq 25)$, Type I (BMI $\geq 30)$, and Type II $(B M I \geq 35)$ obesity among males above 67 years. The empirical model is based on equation (3), where the dependent variable is replaced from BMI25 to BMI30 and to BMI35.

Results support the conclusion that regardless of the benchmark, the projected probability remains unchanged with the annual level of monetary income from a pension ( $p=0.4404, p=0.4225$, and $p=0.5758$, respectively) and with self-reported overall health conditions $(p=0.9232$, $p=0.2439$, and $p=0.3300$, respectively).
Additional outcomes show that for the group of male respondents, the projected probability of type II obesity rises with homeownership by $2.55 \%(p=0.0431)$ to $2.74 \%$ $(p=0.04)$. Narrowing the benchmark of obesity makes the coefficients of Age closer to zero. The projected probability of overweight decreases with the age variable by $0.99 \%$ $(p=0.045)$ to $1.03 \%(p=0.0328)$. However, referring to type I and type II obesity, the coefficient of age remains unchanged ( $p=0.9494$ and $p=0.8297)$. Also, and with the exception of type I obesity, the coefficients of the variables Car, Academic, and IMM_ASIA_AFRICA remain unchanged with respect to the projected probability of overweight and type II obesity. The coefficient of OVERALL_HEALTH remains consistently unchanged ( $p=0.9232, p=0.2439$, and $p=0.33$, respectively).

\section{Discussion}

Following Arbel et al. [4], the objective of the current study is to investigate gender differences and the impact of wealth and monetary income from pensions, sociodemographic variables, and self-assessment of health conditions on the projected probability to become obese in the postretirement age-above 67 years. To the best of our knowledge, these relationships have not been previously explored in the context of gender differences in the postretirement age. The current literature addressed the impact of retirement and occupation on body weight, where few of the research studies used income categories rather than precise monetary income (e.g., [5-9]).

To conduct this research, we make use of an extensive questionnaire concerning the economic and sociodemographic features and health and housing conditions of each respondent asked within the framework of the 2015-2016 longitudinal survey conducted by the Israeli CBS. The survey is representative of the Israeli population and includes information regarding the weight, height, gender, and age of each household member.

Methodologically, the article is divided into two sections. In Section 3, the data are arranged to permit testing the BMI change across one year and to observe whether the BMI measured in 2016 is related to income from a pension as well as the frequency of type I obesity $(B M I \geq 30)$ measured in 2015. The disadvantage of this data structure is information loss associated with individuals without BMI information on both 2016 and 2015 waves. Consequently, in Section 4, we apply the analysis to a conventional panel data structure. 
The findings in Section 3 demonstrate that, on the one hand, for women, the projected BMI drops with income from a pension ( $p=0.022$ for females above 67 years and $p=0.049$ for females above 62 years). On the other hand, the spread around the projection becomes wider with higher income from a pension, indicating more heterogeneity in the BMI measure (BMI between 16.75 and 25.90 for women older than 62 with annual income from a pension of 1 million NIS). As for men, the projected BMI remains unchanged with income from a pension ( $p=0.908$ for males above 67 years and $p=0.566$ for males above 62 years).

Further results from Section 3 demonstrate that, on the one hand, for both genders above 67 years and for men above 62 years, the projected BMI change drops with higher income from a pension $(p=0.013, p=0.039$, and $p=0.007$, respectively). On the other hand, the spread around the projection becomes wider with higher income from a pension, indicating more heterogeneity in BMI change (between $0.70 \%$ and $22.53 \%$ drop for above 67 -yearold women with annual income from a pension of 1 million NIS).

The findings in Section 4 show once again that compared with individual retired women without a pension (a majority of 59.9\%), the projected probability of overweight and type I obesity decreases by $0.41 \% \quad(p=0.0021)$ to $0.95 \%$ $(p=0.0001)$ with an incremental increase of 10,000 NIS. The implication is that wealthier retired female respondents suffer less from obesity. Once again, no such relationship is found among the male participants $(p=0.4225)$. Also, widowed and divorced females seem to suffer more from type I and type II obesity problems. The projected probability for type I obesity rises by $9.25 \%(p=0.0319)$ for divorced and by $6.58 \%(p=0.0419)$ to $11.28 \%(p=0.0048)$ for widowed females. The projected probability for type II obesity rises by $9.83 \%(p=0.0340)$ to $12.44 \%(p=0.0572)$ for divorced and by $5.31 \% \quad(p=0.0377)$ to $9.06 \%$ ( $p=0.0430)$ for widowed females. These findings are supported by Iecovich et al. [28], who discuss the problem of loneliness among the elderly populations. Finally, unlike retired men, retired women exhibit improved awareness to overall health conditions, particularly in the context of obesity. Women who reported on improved overall health conditions are less likely to suffer from overweight and type I and type II obesity by $2.45 \% \quad(p=0.0721)$ to $7.47 \%$ $(p=0.0036)$.

An interesting outcome is obtained when we narrow the definition of obesity from Type I $(B M I \geq 30)$ to Type II obesity $(\mathrm{BMI} \geq 35)$. For both genders, the projected probability of type II obesity increases by $2.55 \%(p=0.0431)$ to $4.37 \%$ ( $p=0.0089)$ with homeownership. The implication is that unlike previous outcomes, for both genders, richer individuals who own a housing unit suffer more from type II obesity.

Future research should explore the relationship between wealth sources and liabilities, such as saving accounts, mortgage balance, assigned credit line, and overdraft balance and obesity for the elderly population. This type of research may be of assistance to welfare and public health experts.

\section{Data Availability}

The data used to support the findings of this study are available from the corresponding author upon request.

\section{Conflicts of Interest}

The authors declare that they have no conflicts of interest.

\section{Acknowledgments}

The authors are grateful to the Israel Social Sciences Data Center (ISDC), the Hebrew University of Jerusalem for provision of project data, and to Yifat Arbel and Miri Kerner for their helpful comments.

\section{References}

[1] J. F. Sallis, E. Cerin, T. L. Conway et al., "Physical activity in relation to urban environments in 14 cities worldwide: a cross-sectional study," The Lancet, vol. 387, no. 10034, pp. 2207-2217, 2016.

[2] World Health Organization, Global Strategy on Diet, Physical Activity and Health, World Health Organization, Geneva, Switzerland, 2018, http://www.who.int/dietphysicalactivity/ $\mathrm{pa} / \mathrm{en} /$.

[3] S. T. Nyberg, G. D. Batty, J. Pentti et al., "Obesity and loss of disease-free years owing to major non-communicable diseases: a multicohort study," Lancet Public Health, vol. 3, no. 10, pp. e490-e497, 2018.

[4] Y. Arbel, C. Fialkoff, and K. Amichai, "What is the optimal housing choice for a minimal BMI?," Economics Bulletin, vol. 38, no. 3, pp. 1313-1337, 2018.

[5] S. Chung, M. E. Domino, and S. C. Stearns, "The effect of retirement on weight," Journals of Gerontology: Series B: Psychological Sciences and Social Sciences, vol. 64B, no. 5, pp. 656-665, 2009.

[6] D. K. Houston, J. Cai, and J. Stevens, "Overweight and obesity in young and middle age and early retirement: the ARIC study," Obesity, vol. 17, no. 1, pp. 143-149, 2009.

[7] M.-Y. Kang, C.-G. Yoon, and J.-H. Yoon, "Influence of illness and unhealthy behavior on health-related early retirement in Korea: results from a longitudinal study in Korea," Journal of Occupational Health, vol. 57, no. 1, pp. 28-38, 2015.

[8] R. N. Rooks, E. M. Simonsick, R. Schulz, S. Rubin, and T. Harris, "Who works among older black and white, wellfunctioning adults in the health, aging, and body composition study?," Gerontology and Geriatric Medicine, vol. 3, article 2333721417727098, 2017.

[9] S. A. Burgard and A. Sonnega, "Occupational differences in BMI, BMI trajectories, and implications for employment status among older U.S. workers," Work, Aging and Retirement, vol. 4, no. 1, pp. 21-36, 2018.

[10] World Health Organization, Obesity and Overweight. Key Facts, World Health Organization, Geneva, Switzerland, 2019, https://www.who.int/en/news-room/fact-sheets/detail/obesityand-overweight.

[11] D. N. Weil, "A review of angus Deaton's the great escape: health, wealth, and the origins of inequality," Journal of Economic Literature, vol. 53, no. 1, pp. 102-114, 2015.

[12] S. H. Preston, "The changing relation between mortality and level of economic development," Population Studies, vol. 29, no. 2, pp. 231-248, 1975. 
[13] A. Deaton, "Policy implications of the gradient of health and wealth," Health Affairs, vol. 21, no. 2, pp. 13-30, 2002.

[14] W. Lutz and E. Kebede, "Education and health: redrawing the Preston curve," Population and Development Review, vol. 44, no. 2, pp. 343-361, 2018.

[15] S. V. Subramanian, E. Özaltin, and J. E. Finlay, "Height of nations: a socioeconomic analysis of cohort differences and patterns among women in 54 low- to middle-income countries," PLoS One, vol. 6, no. 4, Article ID e18962, 2011.

[16] D. Jolliffe, "Overweight and poor? on the relationship between income and the body mass index," Economics \& Human Biology, vol. 9, no. 4, pp. 342-355, 2011.

[17] D. Su, O. A. Esqueda, L. Li, and J. A. Pagán, "Income inequality and obesity prevalence among OECD countries," Journal of Biosocial Science, vol. 44, no. 4, pp. 417-432, 2012.

[18] J. L. Zagorsky, "Health and wealth," Economics \& Human Biology, vol. 3, no. 2, pp. 296-313, 2005.

[19] Y. G. Lee, "Financial status and body mass index of middleaged and older men and women," Journal of Financial Counseling and Planning, vol. 29, no. 1, pp. 19-35, 2018.

[20] A. M. Adachi-Mejia, C. Lee, C. Lee et al., "Geographic variation in the relationship between body mass index and the built environment," Preventive Medicine, vol. 100, pp. 33-40, 2017.

[21] J. H. Stark, K. Neckerman, G. S. Lovasi et al., "The impact of neighborhood park access and quality on body mass index among adults in New York city," Preventive Medicine, vol. 64, pp. 63-68, 2014.

[22] J. Molina-Garc, A. Queralt, M. A. Adams, T. L. Conway, and J. F. Sallis, "Neighborhood built environment and socioeconomic status in relation to multiple health outcomes in adolescents," Preventive Medicine, vol. 105, pp. 88-94, 2017.

[23] J. F. Sallis, T. L. Conway, K. L. Cain et al., "Neighborhood built environment and socioeconomic status in relation to physical activity, sedentary behavior, and weight status of adolescents," Preventive Medicine, vol. 110, pp. 47-54, 2018.

[24] OECD, Pensions at a Glance 2017 OECD and G20 Indicators, OECD, Paris, France, 2017.

[25] D. McCloskey and S. T. Ziliak, "The standard error of regressions," Journal of Economic Literature, vol. 34, pp. 97-114, 1996.

[26] S. T. Ziliak and D. McCloskey, "Size matters: the standard error of regressions in the American economic review," Journal of Socio-Economics, vol. 33, no. 5, pp. 527-546, 2004.

[27] R. L. Wasserstein, A. L. Schirm, and N. A. Lazar, "Moving to a world beyond " $p<0.05$," American Statistician, vol. 73, no. 1, pp. 1-19, 2019.

[28] E. Iecovich, Y. Brick, and Y. Katan, "Services for the elderly population in Israel: the need for a national master plan," Gerontology \& Geriatrics, vol. 1, no. 2, pp. 11-73, 2014.

[29] Israeli Central Bureau of Statistics Press Release, "Dwelling in Israel-findings from the household expenditure survey, 2016 (hebrew)," Israeli Central Bureau of Statistics, Jerusalem, Israel, 2016, http://www.cbs.gov.il/www/hodaot2017n/15_17_ 358b.docx.

[30] Israeli Central Bureau of Statistics, Table 14: Ownership of Durable Goods in Deciles of Households by Net Income per Standard Person, Israeli Central Bureau of Statistics, Jerusalem, Israel, 2015, http://www.cbs.gov.il/publications17/ 1677/pdf/t14.pdf.

[31] Israeli Central Bureau of Statistics, Statistical abstract of Israel: population, by population group, religion, age and sex, district and sub-district, Israeli Central Bureau of Statistics, Jerusalem, Israel, 2018, http://www.cbs.gov.il/shnaton69/st02_19x.pdf.
[32] Israeli Central Bureau of Statistics, Statistical Abstract of Israel: Population Aged 15 and Over by Religion, Marital Statuse, Sex and Age, Israeli Central Bureau of Statistics, Jerusalem, Israel, 2018, http://www.cbs.gov.il/reader/shnaton/templ_ shnaton_e.html?num_tab=st02_04x\&CYear=2018.

[33] Israeli Central Bureau of Statistics Press Release, Life Expectancy in Israel, Israeli Central Bureau of Statistics, Jerusalem, Israel, 2016, http://www.cbs.gov.il/reader/newhodaot/hodaa_ template.html?hodaa=201705362.

[34] Israeli Central Bureau of Statistics, Statistical Abstract of Israel: Immigrants by Period of Immigration and Last Continent of Residence, Israeli Central Bureau of Statistics, Jerusalem, Israel, 2018, http://www.cbs.gov.il/reader/shnaton/templ_ shnaton_e.html?num_tab=st04_02\&CYear=2018.

[35] J. Johnston and J. Dinardo, Econometric Methods, McGrawHill International Edition, New York, NY, USA, 4th edition, 1997.

[36] W. H. Greene, Econometric Analysis, Pearson Education Limited, Bengaluru, India, 7th edition, 2012. 


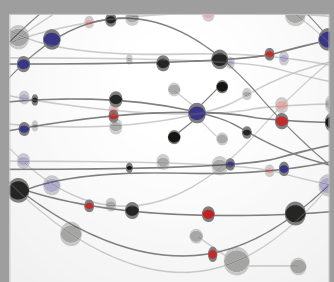

The Scientific World Journal
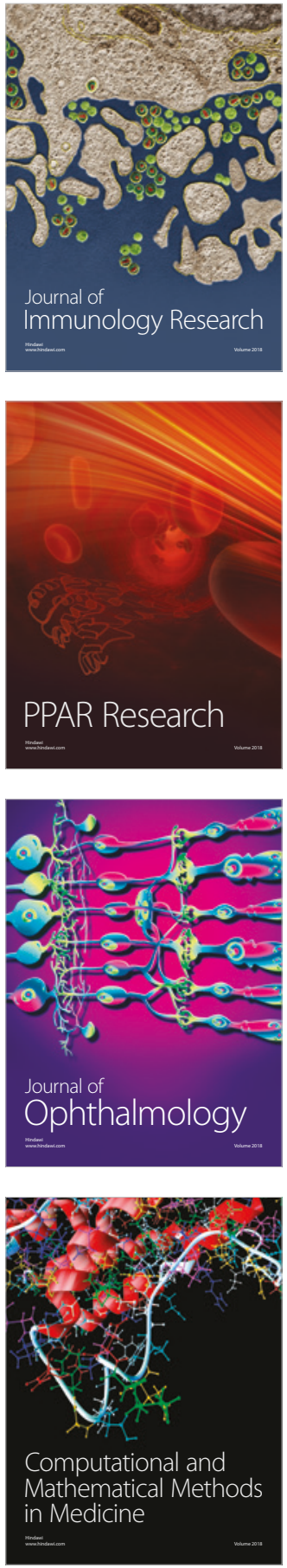

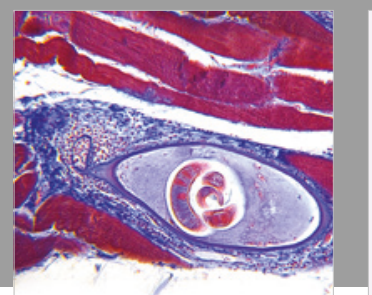

Gastroenterology Research and Practice

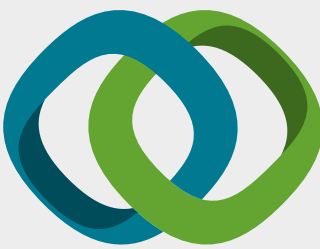

\section{Hindawi}

Submit your manuscripts at

www.hindawi.com
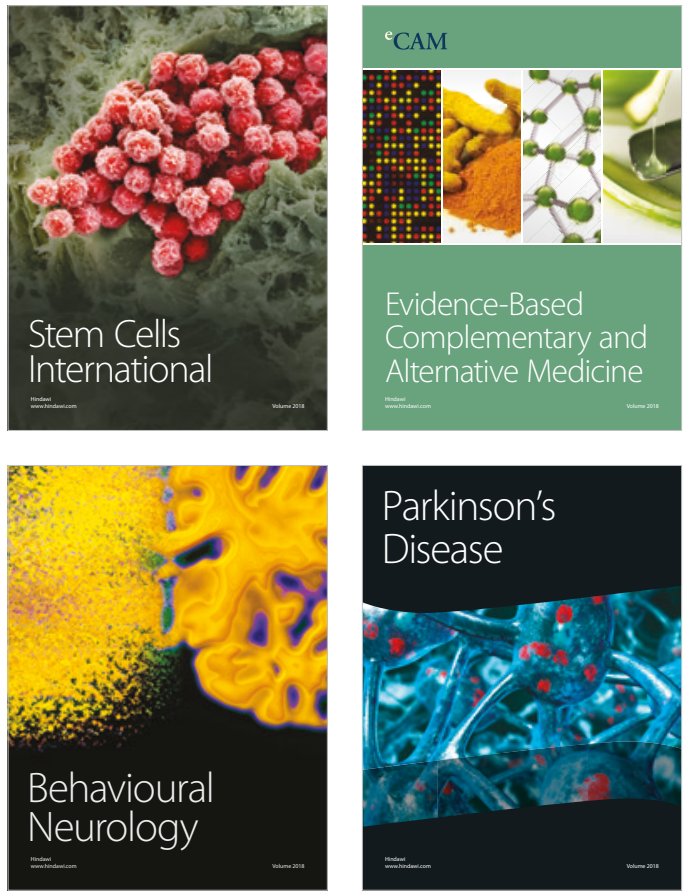

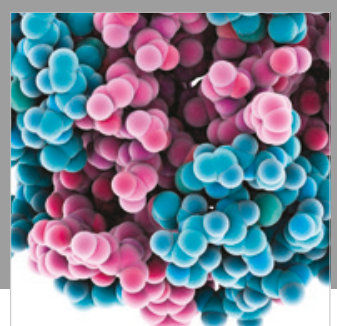

ournal of

Diabetes Research

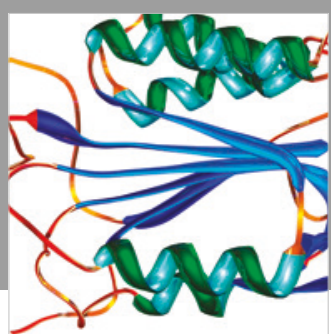

Disease Markers
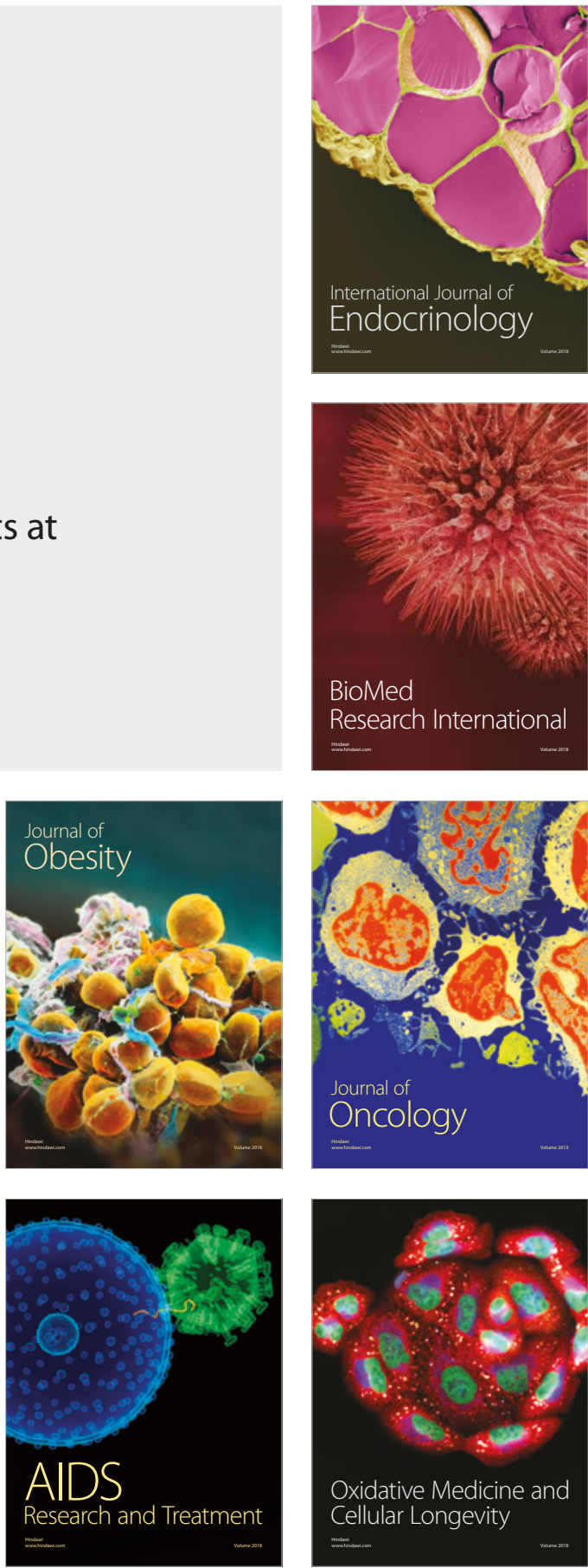